\title{
Safety Evaluation Report Restart of K-Reactor Savannah River Site
}

\section{Supplement 2}

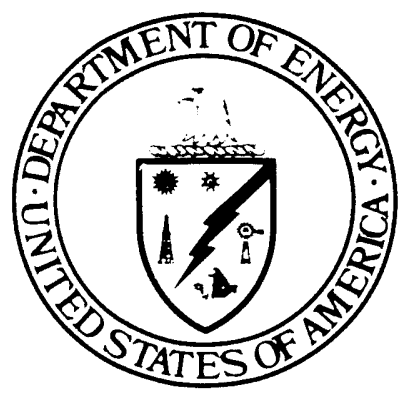

\section{October 1991}

\author{
U.S. Department of Energy \\ Assistant Secretary for Defense Programs \\ Deputy Assistant Secretary for Facilities
}

Washington, D.C. 20585 


\section{TABLE OF CONTENTS}

Page

$1 \quad$ Introduction $\ldots \ldots \ldots \ldots \ldots \ldots \ldots \ldots \ldots \ldots \ldots \ldots \ldots \ldots$

2.1 DOE Management and Program Oversight $\ldots \ldots \ldots \ldots \ldots \ldots \ldots$

2.3 Management and Safety Culture $\ldots \ldots \ldots \ldots \ldots \ldots \ldots \ldots \ldots$

2.5 Contractor Compliance with DOE Orders $\ldots \ldots \ldots \ldots \ldots \ldots \ldots$

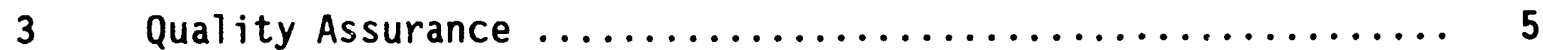

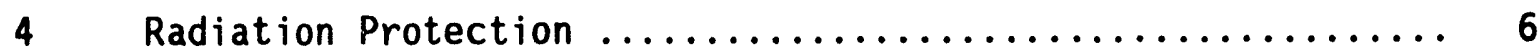

5.2 Unreviewed Safety Questions (USQs) $\ldots \ldots \ldots \ldots \ldots \ldots \ldots \ldots \ldots$

5.3 Technical Baseline Program ..................... 18

5.4 Design Change Process $\ldots \ldots \ldots \ldots \ldots \ldots \ldots \ldots \ldots \ldots \ldots \ldots \ldots$

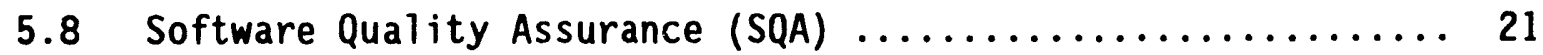

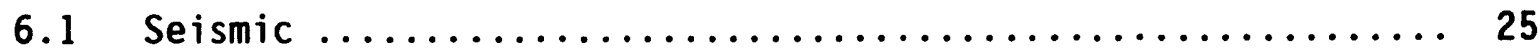

6.3 .2 Environmental Qualification $\ldots \ldots \ldots \ldots \ldots \ldots \ldots \ldots \ldots \ldots \ldots \ldots \ldots \ldots \ldots$

6.6 Sump Water Removal $\ldots \ldots \ldots \ldots \ldots \ldots \ldots \ldots \ldots \ldots \ldots \ldots \ldots \ldots$

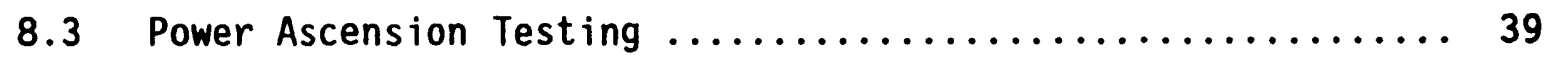

10.3 Normal and Abnormal Operating Procedures .............. 40

10.4 Emergency Operating Guidelines and Procedures .......... 43

13 Maintenance $\ldots \ldots \ldots \ldots \ldots \ldots \ldots \ldots \ldots \ldots \ldots \ldots \ldots \ldots \ldots \ldots$

15 Emergency Preparedness ....................... 47

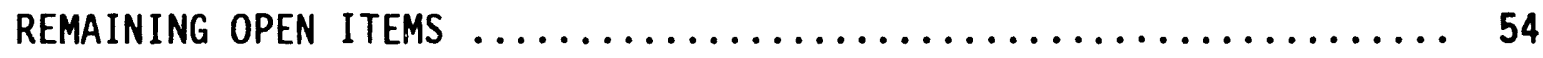


In Apri1 1991, the Department of Energy (DOE) issued DOE/DP-0084T, "Safety Evaluation Report Restart of K-Reactor Savannah River Site." The Safety Evaluation Report (SER) documents the results of DOE reviews and evaluations of the programmatic aspects of a large number of issues necessary to be satisfactorily addressed before restart. The issues were evaluated for compliance with the restart criteria included in the SER. The results of those evaluations determined that the restart criteria had been satisfied for some of the issues. However, for most of the issues at least part of the applicable restart criteria had not been found to be satisfied at the time the evaluations were prepared. For those issues, open or confirmatory items were identified that required resolution.

In August 1991, DOE issued DOE/DP-0090T, "Safety Evaluation Report Restart of K-Reactor Savannah River Site Supplement 1." That document was the first Supplement to the April 1991 SER, and documented the resolution of 62 of the open items identified in the SER.

This document is the second Supplement to the April 1991 SER. This second SER Supplement documents the resolution of additional open items identified in the SER, and includes a complete list of all remaining SER open items. The resolution of those remaining open items will be documented in future SER Supplements. Resolution of all open items for an issue indicates that its associated restart criteria have been satisfied, and that DOE concludes that the programmatic aspects of the issue have been satisfactorily addressed. 


\subsection{DOE Management and Program Oversight}

Open Item: Publish SRSPO insiructions, guidelines, and procedures prior to restart.

The final procedure required to be approved for restart, AI-113, "Nuclear Facility Restart Procedure," was approved by the Deputy Assistant Secretary for Facilities on September 16, 1991. This item is closed.

Open Item: SRSPO managers, facility representatives, and staff must complete their respective mandated restart training requirements.

A Restart Task Force (RTF) was established in an effort to better focus training and personnel resources as described in AI-108, "DOE Monitoring of K-Reactor Restart Evolutions by the DOE Restart Task Force." SRSPO staff received varying levels of training dependent upon their positions relative to the RTF. In order to maximize training and personnel resources, all segments of required restart training were completed by RTF members in accordance with paragraph B.4 of AI-108, which states that RTF management personnel and Facility Representatives will be trained in accordance with AI-106, "Training." The last remaining area of restart training required the RTF managers, including the Director of SRSPO, to become familiar with "lessons learned at DOE facilities." This final training requirement was fulfilled by viewing of the video "Lessons Learned at DOE" on September 14, 1991. This item is closed.

There is one open item remaining to be resolved for this issue. 


\subsection{Management and Safety Culture}

Open Item: WSRC must document that the plant manager shall be responsible for a)1 aspects of reactor operation, including those identified in the restart criteria.

Procedure RP 2.10301, "Reactor Operations Department Organization and Responsibilities," Revision 2, dated July 26, 1991, with an effective date of September 13, 1991, included in the Conduct of Operations Manual R2.1, was revised to include the Plant Manager's responsibilities. Section 4.3.3 of the procedure documents that the Plant Manager is responsible for all aspects of reactor operation, including those identified in the restart criteria. Therefore, this item is closed.

All open items have been resolved for this issue. 


\subsection{Contractor Compliance with DOE Orders}

Open Item: Identify the DOE Orders for which compliance is being assessed and confirm that all Level I DOE Orders are included.

In an attachment to WSRC letter ESH-AAC-910334, dated July 12, 1991, WSRC identified 93 Level 1 DOE Orders for which compliance is being assessed. Although the SER identified only 85 Level 1 DOE Orders, the list is maintained current and periodically updated as new orders are issued or existing orders are revised or incorporated into new orders. Also, orders were added to the list as a result of subsequent reviews determining that the list was incomplete.

The list of 85 Level 1 DOE Orders contained in the SER has been updated by adding nine orders, revising two orders, and deleting one order, as shown below:

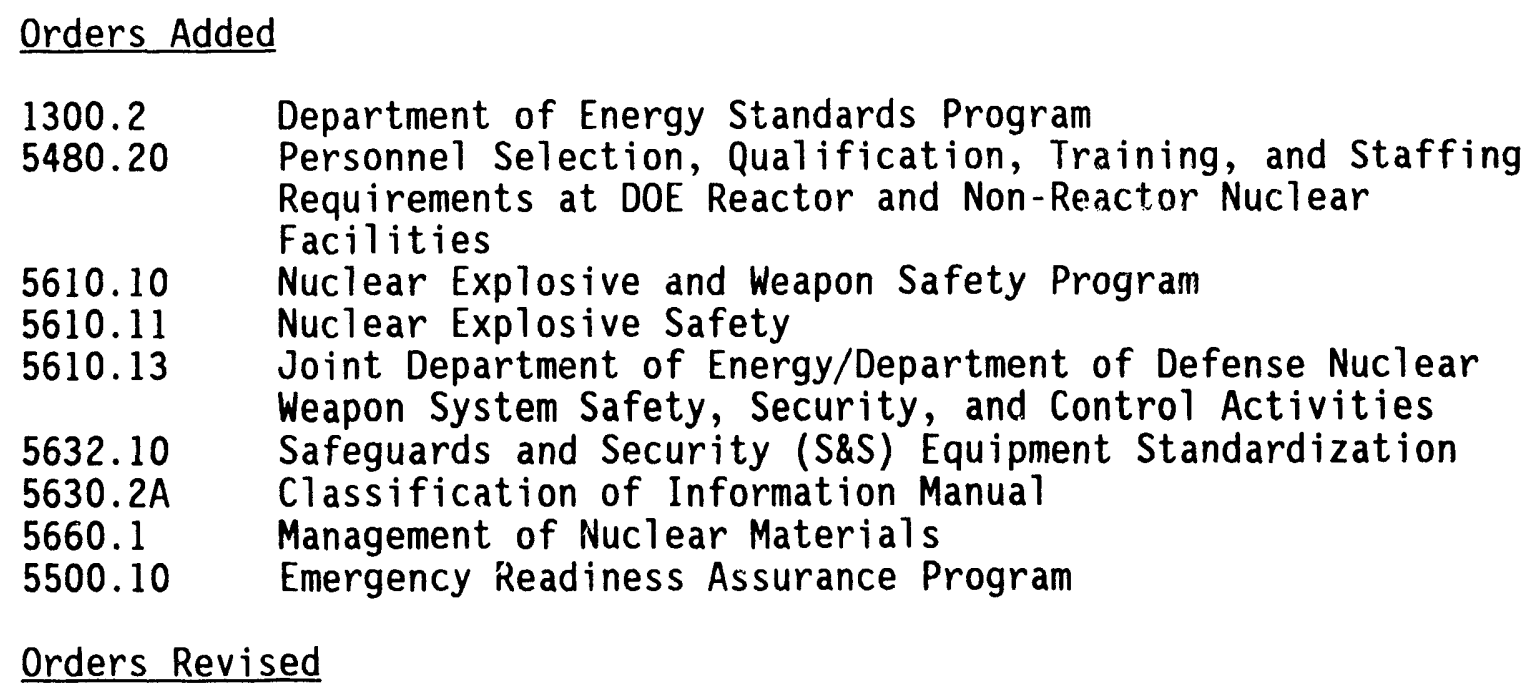

The updated list now consists of 93 Level 1 DOE Orders, and is consistent with the list identified by WSRC. Therefore, this item is closed.

There are four open items remaining to be resolved for this issue. 
Open Item: Completion of the 41 QA-related Restart Work Items (RWIs) identified in the Reactor Operations Management Plan (ROMP).

The 41 QA ROMP closure packages provided by WSRC were reviewed by the DOE staff, and were also subjected to field verification, as appropriate. Each closure package was approved when it was concluded that the work scope required by the restart work item had been completed, and the deliverables had been produced in a formal manner. The last of the procedures for the QA program upgrade, RP 5-1306, "Reactor Engineering Database Controls," Revision 0 , was issued on September 16, 1991. A11 of the 41 QA ROMP packages have been completed, reviewed, and formally approved by DOE. Therefore, this item is closed.

All open items have been resolved for this issue. 
Open Item: Compliance with American National Standards Institute (ANSI) industry standard N319-1976, "Personnel Neutron Dosimeters (Neutron energies less than $20 \mathrm{MeV}) "$.

WSRC performed an assessment to determine the status of compliance with ANSI N319-1976. WSRC-RP-90-12, "Environmental Protection, Safety, and Health Protection Standards," Revision 0, dated July 11, 1991, reported full compliance except that tests had not been performed to verify that TLD performance would still be in compliance with ANSI N319 criteria after being subjected to the environmental extremes listed in Section 4.5 of ANSI N319-1976. Subsequently, WSRC memorandum, "ANSI N319-1976 Compliance", from S.G. Dyer to M. D. Matheny, dated August 26, 1991, reported the performance of environmental tests which demonstrated full compliance of the WSRC neutron dosimetry program with ANSI N319-1976.

The WSRC dosimetry system performance capabilities and test data, as provided to DOE in closeout package ESH-HPC-910185, "Closure Package", dated vuly 26, 1991, and the final WSRC Compliance Review of DOE Order 5480.4, contained in WSRC-RP-90-12, "Environmental Protection, Safety, and Health Protection Standards," Revision 2, dated September 20, 1991, was reviewed by the DOE staff. Based on this information, compliance with ANSI N319-1976 is confirmed. This item is closed.

Open Item: Lack of progress on assigning adequate resources for performing internal audits of all the functional elements of the Radiation Protection Program.

DOE Order 5480.11, "Radiation Protection for Occupational Workers", section 9.1, requires internal audits of all functional elements of the radiation protection program as often as necessary but no less frequently than every three years. In response to the root causes identified in the DOE-HQ report, "Health Physics Review of Savannah River Plant", dated September 1988, WSRC stated in ESH-TMA-89-0003, "US DOE Headquarters Review on Health Physics of the Savannah River Site", dated January 23, 1989, that the number of professional health physicists assigned solely to internal audits would be increased and that internal audits would then be conducted of all functional elements annually. WSRC reevaluated their annual audit commitment and staffing requirements in order to implement a three year audit cycle of the 12 functional program elements. This resulted in assigning a staff of five plus a group leader to the internal audit program. The contractor's Radiation Protection internal audit program is documented in WSRC manual 5Q, "Savannah River Site Radiological Controls", Revision 0, dated August 1, 1991, and implementing document Q1-1 404, "Internal Appraisals", Revision 4, dated August 1, 1990.

A DOE staff review of WSRC manual 5Q and Q1-1 404 indicated appropriate procedural guidance is now in place. Of the 12 major health physics functional elements identified in the Order and included in the WSRC documents, six have been completed and the remaining six are scheduled to be completed within the required time frame. A review was made of samples of the 
first six audit reports. Findings were identified properly against

appropriate criteria. Review of responses to the findings by the applicable Reactor Area HP managers describing corrective action taken or planned to prevent recurrence of the problems has been completed. This item is closed.

Open Item: Resolve weaknesses in the internal Radiation Monitoring Program discovered during an assessment of the contractor's personnel dosimetry program that was underway when the SER was being prepared.

WSRC-IM-90-139, "Internal Dosimetry Technical Basis Manual," Revision 0, dated December 20, 1990, was issued and contains the technical bases for the internal dosimetry program, including recommended bioassay programs for both worker and work-group monitoring. Reactor area implementing procedures for the internal dosimetry program are as follows:

- DPSOL 100-9707, "Bioassay Sampling - Tritium (all reactor area departments and construction", Revision 12, dated Apri1 26, 1989

o 5Q1.2-211, "Routine Invivo and Invitro Bioassay Scheduling and Administration", Revision 1, dated Apri1 1, 1991

- 5Q1.2-212, "Special Bicassay Measurements", Revision 1, dated Apri1 1, 1991

o 5Q1.2-213, "Tritium Control", Revision 1, dated Apri1 1, 1991

An appraisal of the Savannah River Site (SRS) Internal Dosimetry Program was conducted by a joint team from DOE-SRSPO and the DOE-SR operations office from January 22 to March 12, 1991. The results are documented in RS-91-AP-02, "Radiation Safety Functional Appraisal of the Savannah River Site Internal Dosimetry Program", dated July 1991. The appraisal objective was to evaluate the incorporation of Department of Energy (DOE) requirements and other applicable guidance into internal dosimetry operating procedures and conformance to those procedures. As a result of this appraisal and DOE staff verification of performance of corrective follow-up actions by the contractor, as reported in DOE-SR, F008480, "Internal Dosimetry Program - Corrective Actions," dated July 2, 1991, the WSRC Internal Dosimetry Program now meets the requirements of DOE Order 5480.11. This item is closed.

Open Item: Complete an assessment to determine an appropriate number and placement of fixed nuclear accident dosimeters in the reactor facility.

The contractor has completed an evaluation of the adequacy of placement of fixed criticality neutron dosimeters (CNDS), as documented in a WSRC internal memorandum from D.E. Perkins to H.J. Stafford dated May 23, 1991. The recommendations derived from the evaluation included the relocation of four CNDs and the addition of another three CNDs. In the WSRC document ESH-HPC-910173, "Fixed Criticality Neutron Dosimeters", dated July 25, 1991, the recommendations were approved for implementation. In WSRC Interim Procedure, 5Q1.2-215A, "Procedure for Evaluation of Location of Fixed Criticality Neutron Dosimeters", Revision 1, dated March 8, 1991 the contractor has also committed to an annual first quarter appraisal of the CND program. The appraisal would include placement of CNDs, inspection of installed CNDs, and an assessment of the impact of changes in the structural and operational features of the facility. 
A DOE staff review of the following supportive documents was conducted:

1. Memorandum from D. E. Perkins to H. F. Stafford, "Evaluation of Fixed CND Placement in K-Reactor Facility", dated March 23, 1991;

2. Memorandum from M. D. Matheny to H. J. Stafford, "CND Placement", dated July 15, 1991; and

3. Memorandum from H. F. Stafford to D. M. Hall, "CND Placement Update", dated July 23, 1991.

Based on the review of documentation and a DOE staff verification of the implementation of the recommendations, this item is closed.

Open Item: Resolution of a weakness in the Radiation Monitoring Program. A DOE review of the quality assurance program for measuring and test equipment used for radiation monitoring indicates significant weaknesses in the calibration program for radiation monitoring instruments.

Weaknesses in the Radiation Protection Program that were identified by the DOE review involve (1) adequacy of the quality assurance program for calibrating portable measuring and test equipment (M\&TE) used for radiation monitoring, and (2) the adequacy of WSRC's documentation of a technical basis for portable instruments used to monitor radiation.

WSRC has taken the following actions to resolve weaknesses in the calibration program for M\&TE used for radiation monitoring:

(a) WSRC has assessed the Heilth Protection Technology (HPT) Instrumentation Calibration Program for conipliance with ANSI N323-1978, "Radiation Protection Instrumentation Test and Calibration." The results are documented in WSRC-RP-90-12, "DOE Order 5480.4 Compliance Package", Revision 2, dated September 20, 1991. WSRC also issued a Compliance Schedule Approval (SRS-DOE-5480.4-CSA-37) request addressing areas of noncompliance.

(b) The WSRC HPT staff issued procedures Q2-114, "Instrument Requests, Wrapping and Disbursement", Revision 5, dated August 31, 1991, and Q2-115, "Instrument Receipt and Inspection", Revision-0, dated August 1, 1991, which provide accountability for M\&TE (i.e., portable radiation monitoring instruments) that is received from and disbursed to the K-Reactor facility. Additionally, procedure Q1-1-613, "Control of Measuring and Test Equipment", Revision 1, dated Apri1 10, 1991, implements the requirements of procedure QAP-12-1, "Control of Measuring and Test Equipment", Revision 0, dated April 1, 1990, for control of M\&TE used for radiation monitoring.

(c) The K-Reactor facility Health Protection Operations (HPO) staff issued a memorandum, "Implementation of Manual 5Q1.3 - Procedure 144(U)", G.R. Schramm to H.J. Stafford, dated September 21, 1991, which (a) requires a complete inventory of ail portable radiation survey instruments and a comparison of the inventory results to the instrument 
list supplied by Calibrations; and (b) establishes a daily administrative routine to source check all instruments, thereby providing a daily accounting of all M\&TE used for radiation monitoring.

(d) The HPT Calibration Group issued procedure Q2-118, "Instrument Recall", Revision 0, dated September 20, 1991, for calibration recall of M\&TE radiation monitoring instruments from K-Reactor facility. The procedure provides instructions for recalling survey instruments whose calibration has expired or is due to expire within the next two weeks.

With respect to documenting a technical basis for monitoring of contamination and radioactive material, WSRC issued a technical basis document WSRC-IM-91-20, "Technical Basis: Savannah River Site Portable Radiation Protection Instrumentation", Revision 0, on September 1, 1991.

DOE has reviewed the HPT procedures Q2-114, Q2-115, Q2-118, and Q1-1-613; the memo issued by K-Reactor facility HPO; and the WSRC Compliance Package for DOE Order 5480.4 with respect to ANSI N323-1978. Compliance with these documents provide an adequate program of control and accountability for M\&TE used for radiation monitoring at K-Reactor facility.

A review of Manual WSRC-IM-91-20 concludes that this manual adequately documents the technical basis for the portable radiation protection instrumentation in use at K-Reactor facility for monitoring radioactive material and contaminated areas. This item is closed.

Open Item: Compliance with ANSI N320-1979, "Performance Specifications for Reactor Emergency Radiological Monitoring Instrumentation".

WSRC performed a Compliance Review, documented in WSRC-RP-90-12, "DOE Order 5480.4 Compliance Package," Revision 2, dated September 20, 1991, and determined that requirements of ANSI N320-1979, with respect to portable survey instruments, air samples and direct reading dosimeters, were being met.

Section 5.2.5, "Radiological Monitoring Instrumentation," of the Compliance Package stated "with respect to portable survey instruments used during reactor emergencies, WSRC is in full compliance with ANSI N320-1979 by having available the Eberline Model RO-7-BH High Range Detector coupled with either the Bicron Model RSO-50 or Model RSO-500 instruments." However, neither the Model RSO-50 or Model RSO-500 are compatible with a Model R0-7-BH High Range Detector. In addition, these survey meters are not capable of measuring exposure rates over the range specified in Section 9.1.2 of ANSI N320-1979.

WSRC letter to DOE, ESH-HPC-910254, "HPO Emergency Equipment," dated September 23, 1991, commits to having Eberline Model RO-7 with a Model RO-7-BH High Range Detector survey instruments for portable instruments to be used during reactor emergencies. A review of the manufacturer's specifications for these instruments determined the instruments are in compliance with applicable requirements contained in Section 9 of ANSI N320-1979. 
A review of procedure EPIP 6Q7-303, "Emergency Equipment and Supplies", Revision 1, dated August 13, 1991, determined the correct type of direct reading dosimeters and portable air samplers are maintained for emergency use.

Based on the contractor's commitment to have available Model R0-7 survey instruments with Model RO-7-BH detectors, the contractor is in compliance with the applicable sections of ANSI N320-1979 on portable monitoring instrumentation. This item is closed.

Open Item: Compliance with DOE Order 5820.A, "Radioactive Waste Management", namely development and implementation of an effective radioactive waste management program utilizing reduction in generation of waste, segregation of clean waste from radioactive waste, and volume reduction of the remaining radioactive component.

DOE Order 5820.2A, "Radioactive Waste Management," Chapter III, "Management of Low-Level Waste", Section 3.c, "Requirements for Waste Generation", requires technical and administrative controls to be directed to reducing the gross volume of waste generated and the amount of radioactivity requiring disposal.

Areas of DOE concern, as stated in the April 1991 SER, involve programs to ensure minimization and segregation of radioactive wastes. An effective waste minimization program should have at least three basic elements: (1) screening of materials brought into the Radiologically Controlled Areas (RCAs) in order to reduce the volume of material that may become contaminated, (2) survey of materials removed from RCAs to segregate the non-contaminated waste from the volume of contaminated waste, and (3) a method of reducing the volume of waste destined for disposal.

The operating contractor has taken the following actions to comply with the requirements of Order $5820.2 \mathrm{~A}$ :

1. Establishment of a Radwaste Management Group in the Reactor Restart Division (RRD);

2. Issuance of the "RRD Waste Minimization Plan", Revision 0, dated July 24, 1991, approved by the Vice President, Reactor Restart Division, WSRC; and

3. Issuance of an implementation schedule for the RRD Waste Minimization Plan.

The RRD Waste Minimization Plan has been reviewed and found to adequately address all the required basic elements specified in the April 1991 SER. The contractor's RRD-ROSS-910074, "RRD Waste Minimization Plan Implementation Schedule", dated September 21, 1991, provides the milestone schedule to fully implement the RRD Waste Minimization Plan. The organization and staffing levels of the RRD Radwaste Management Group appears adequate to impiement the RRD Waste Minimization Plan. This item is closed. 
Open Item: Resolution of the effectiveness of the Westinghouse Government Operations Nuclear Safety and Environmental Oversight Committee, as an oversight group, to critique the specific facets of the SRS radiation protection program.

In D0E/EH-0085, "Health Physics Review of Savannah River Plant", dated September 1988, and performed by the Office of Safety Policy and Standards ( $\mathrm{NOE}-\mathrm{EH} / \mathrm{HQ}$ ), several root causes of weaknesses were identified in the site radiation protection program. Among these was an apparent lack of effective management controls. In response to the review, the operating contractor committed, in letter ESH-TMA-89-0003, "US DOE-HQ Report on the Health Physics Review of the Savannah River Plant (SRP) dated January 23, 1989," dated April 19, 1989, to the local DOE Field Office to implement several corrective actions. The aciion to be taken in response to the concern of the lack of effective managemerit controls was to establish a multi-level oversight program to monitor and ensure procedural compliance. One level was to be provided by the Westinghouse Government Operations Nuclear Safety and Environmental Oversight Committee. The Oversight Committee is composed of experts from industry and academia. They were to improve radiation protection at SRS by performing in-depth appraisals of the SRS program beginning in October 1989 and continuing annually. The committee has made two visits to SRS to date.

A study of the reports resulting from the site visits indicated the scope of their review was much broader than expected and therefore failed to examine the radiation protection program as closely as had been envisioned. The contractor has concurred, as stated in letter ESH-PAS-910068, "K-Reactor Safety Evaluation Report, Item SER-042(U)," from G. Tunno, WSRC-HPD to R. L. Huskin, DOE-SRSPO, dated June 19, 991 , with DOE's observation that the reviews, although beneficial, were not conducted at a sufficient level of detail to monitor procedural compliance. Therefore, it is concluded the Oversight Committee is not an effective means to conduct appraisals to the depth intended in the original commitment.

However, in light of a renewed commitment, as documented in a letter from D. A. Stevenson, HPO-WSRC to L. C. Bogar, VP-Westinghouse Environmental Management of Ohio (WEMO), "Westinghouse GOCO Radiation Safety Managers Committee Appraisals," dated September 19, 1991, by the operating contractor to subject it's radia" sgical protection program to review by the Westinghouse GOCO Radiation Safet, Managers Committee, the DOE staff concludes that the intent to provide indepondent review of the SRS Radiological Protection program is being adequaiely addressed. This item is closed.

Open Item: Complete audit by a committee of Health Physicists from various other Westinghouse-operated Government Owned/Contractor Operated (W-GOCO) sites.

In DOE/EH-0085, "Health Physics Review of Savannah River Plant", dated September 1988, and performed by the Office of Safety Folicy and Standards (DOE-EH/HQ), several root causes of weaknesses were identified in the site radiation protection program. Among these was an apparent lack of effective management controls. In response to the review, the operating contractor 
committed, in letter ESH-TMA-89-0003, "US DOE-HQ Report on the Health Physics Review of the Savannah River Plant (SRP) dated January 23, 1989," dated April 19, 1989, to the local DOE Field Office to implement several corrective actions. The action to be taken in response to the concern of the lack of effective management controls was to establish a multi-level oversight program to monitor and ensure procedural compliance. One level was to be provided by the Westinghouse-GOCO Oversight Committee comprised of experienced radiation protection personnel from other Westinghouse operated facilities. A review of their findings, as documented in a letter from M. Heyland to D. Stevenson, "Westinghouse GOCO 5480.11 Compliance Review", dated April 22, 1991, indi iated the types of issues which should be addressed to improve the effectiveness of the Health Protection Program, and also provided indication of potential management weaknesses.

The contractor has sponsored a plan for continual GOCO appraisals of the Savannah River site radiological protection program, described in a letter from D. Stevenson to L. Bogar, "Westinghouse GOCO Radiation Safety Managers Committee Appraisals", dated September 19, 1991. The proposed schedule is a minimum of every two years.

Based on the evidence provided by the contractor to address the oversight program commitment, this item is closed.

Open Item: Provide documentation of a technical basis for the new whole body friskers and portal monitors acquired to support a portion of the action plan for MS-11.1 to upgrade equipment.

Since 1989, the operating contractor has procured 120 Eberline PCM-1B automated whole-body "friskers" and over 70 "walk-through" type Eberline PM-6 portal monitors for site wide use. Twelve PCM-1Bs and six PM-6s are utilized at the K-Reactor facility. The PCM-1Bs are placed at primary exits from radiological areas and Radiological Controlled Areas (RCAs), while the PM-6s are located at the exit from K-Reactor facility's Limited Security Area (i.e., the outer perimeter).

A study of the sensitivity, calibration requirements and operating parameters was performed to determine the optimum operational characteristics of the devices. This was reported in ESH-HPC-910156, "SRS Personnel Contamination Monitoring Program", dated July 10, 1991.

DOE has reviewed the WSRC document, ESH-HPC-910157, "Closure Package - SER 4.0-39", dated July 10,1991, and concludes that this package adequately documents the technical basis for use of the monitoring equipment at $K$-Reactor facility. This item is clcsed.

Open Item: Provide an entry control mechanism to identify minors and prevent their entry into Radiologically Controlled Areas (RCAs) where they may exceed limiting values for radiation exposure.

WSRC Manual 5Q, "SRS Radiological Control Program", Revision 1, dated August 2, 1991, prohibits the access of people under the age of 18 to radiological areas. Additionally, access to Radiologically Cüntrolled Areas 
(RCAs) is allowed only with permission of the Manager of Health Protection Operations. The implementing document, procedure 5Q1.2-217, "TLD Badges", Revision 3 (w/FCN \#66), dated July 1, 1991, has been revised to require verification that recipients of Temporary TLD badges must be 18 years of age or older. To support the access control program, TLD badges are required to be worn by a 71 personnel entering RCAs.

DOE has reviewed the Health Protection Department procedures on access control. Compliance with these documents provides adequate programs for control of access of minors and students to radiological areas within the K-Reactor facility. This item is closed.

Open Item: Provide an entry control mechanism to maintain positive control of access to RCAs by the public.

In an Employee Communication, "Implementation of Reactor Access Control," from C. L. Peckinpaugh to Distribution, dated December 18, 1990, WSRC stated that effective January 1, 1991, all personnel entering the K-Reactor facility protected area were to have completed General Employee Training or be escorted by an individual who has had such training. In addition, WSRC issued memorandum ESH-HPC-900235, "Reactor Radiation Worker Training (RWT)

Verification," H. J. Stafford to Distribution, dated October 30, 1990, also effective January 1, 1991, requiring all personnel entering RCAs at the K-Reactor facility to have completed Radiation Worker Training, both Core and 100-Area Specific, or be escorted by an individual who has had such training. One objective of the entry requirements is to limit access of individuals not familiar with radiological safety requirements and to provide a positive means of ensuring all who enter controlled areas understand the necessity of wearing the proper radiation monitoring devices (i.e., Thermoluminescent Dosimeter (TLD) badges).

Physical controls consist of postings at the entrance to the facility Protected Area and having Health Protection (HP) Inspectors stationed at the main entrances to the primary RCA. The Protected Area posting is located at the entrance to the security gatehouse and states the requirement for individuals to wear a TLD badge when entering the area. HP Inspectors stationed at the main entrances to the primary RCA require individuals to display their TLD badge and present proof of both a current Fastscan (a form of whole-body count) and Radiation Worker Training (RWT) qual ification. Individuals who are not RWT qualified must be escorted by an individual who is qualified.

Other documents and procedures issued to provide guidance for this program include:

- WSRC Manual 5Q, "SRS Radiological Controls Manual, "Revision 1, dated August 2, 1991;

- WSRC Procedure 5Q1.2-118, "Radiological Postings," Revision 2, dated October 30, 1991; 

Revision 2, dated Apri1 1, 1991; and

- WSRC Procedure 5Q1.2-221, "Radiological Control Points," Revision 0, dated May 1, 1990.

DOE has reviewed the procedures and memoranda on access control. Compliance with these documents provide adequate programs for control of access of the public to controlled areas within the K-Reactor facility. This item is closed.

Open Item: Resolve weaknesses in the External Radiation Monitoring Program such as: (1) lack of a program to ensure worker compliance with requirsilents to wear personal radiation monitoring devices (i.e., TLD badges) when inside the reactor facility's "Protected Areas" fence, (2) no requirement to promptly investigate and resolve lost or unreturned TLD badges, and (3) discrepancies discovered during an assessment of the contractor's personnel dosimetry program that was underway when the SER was being prepared.

Concerning a plan to ensure workers wear TLD badges when inside the K-Reactor facility Protected Area, the following activities have taken place.

In an Employee Communication, "Implementation of Reactor Access Control, " from C. L. Peckinpaugh to Distribution, dated December 18, 1990, WSRC stated that effective January 1, 1991, all personnel entering the K-Reactor facility protected area were to have completed General Employee Training or be escorted by an individual who has had such training. In addition, WSRC issued memorandum ESH-HPC-900235, "Reactor Radiation Worker Training (RWT) Verification," H. J. Stafford to Distribution, dated October 30, 1990, also effective January 1, 1991, requiring all personnel entering RCAs at the K-Reactor facility to have completed Radiation Worker Training, both Core and 100-Area Specific, or be escorted by an individual who has had such training. One objective of such entry requirements is to 1 imit access of individuals not familiar with radiological safety requirements and to provide a positive means of ensuring all who enter controlled areas understand the necessity of wearing the proper radiation monitoring devices (i.e., Thermoluminescent Dosimeter (TLD) badges).

Physical controls consist of postings at the entrance to the facility Protected Area and having Health Protection (HP) Inspectors stationed at the main entrances to the primary RCA. The Protected Area posting is located at the entrance to the security gatehouse and states the requirement for indiviciuals to wear a TLD badge when entering the area. HP Inspectors stationed at the main entrances to the primary RCA require individuals to display sheir TLD badge and present proof of both a current Fastscan (a form of whole-body count) and Radiation Worker Training (RWT) qualification. Individuals who are not RWT qualified must be escorted by an individual who is qualified. 
Other documents and procedures issued to provide guidance for this program include:

- WSRC Manual 5Q, "SRS Radiological Controls Manual," Revision 1, dated August 2, 1991 ;

o WSRC Procedure 5Q1.2-118, "Radiological Postings, "Revision 2, dated October 30, 1991;

- WSRC Procedure 5Q1.2-220, "Hea1th Protection Requirements for Visitors," Revision 2, dated Apri1 1, 1991; and

0

WSRC Procedure 5Q1.2-221, "Radiological Control Points," Revipion 0, dated May 1, 1990.

The results of the assessment of the contractor's personnel dosimetry program are documented in RS-91-AP-03, "Radiation Safety Functional Appraisal of the Savannah River Site External Dosimetry Program," DOE-SR/FSD, dated July 1991. Ten findings were noted. Of these, eight dealt with non-compliances with one or more DOE Orders. One of those findings concerned Section 9.g.(1), "External Radiation Monitoring," of DOE Order 5480.11. Specifically, the current program for issuance and control of TLDs does not ensure accurate monitoring or reporting of dose. Subsequent corrective actions and program improvements resulted in resolution of the findings and compliance with the requirements of Section 9.9 . (1) of DOE Order 5480.11 . Corrective actions underway were determined by DOE-SR to be acceptable to address the noncompliance (Letter T. F. Heenan to R. R. Campbe11, dated July 29, 1991). Compliance is documented in WSR -RP-90-12, "DOE Order 5480.11 Compliance Package," Revision 4, dated August 21, 1991.

Concerning the process to follow through on lost or unreturned TLD badges in a timely manner, the following activities have taken place.

WSRC has reviewed it's program for initiating investigations of TLD badges not returned at the end of each monthly badge cycle. After considering a number of factors, such as the large number of badges which miss the first collectior date, it was determined that the optimum time at which to initiate the appropriate investigation is after the badges from the next monthly cycle are collected. This allows for the majority of "late" badges to be collected through normal channels. To implement this change in the program, the contractor is presently revising WSRC Procedure 5Q1.2-107, "Exposure Investigation." The revision is expected to be implemented by December 31, 1991. This issue was captured in the assessment of the personnel dosimetry program discussed above and the resolution was determined to be acceptable by DOE.

DOE has reviewed the procedures and correspondence on access control, TLD investigations and resolution of the assessment findings. Compliance with these documents provide adequate programs for control of access to radiological areas within the K-Reactor facility and monitoring of external radiation. This item is closed. 
Open Item: Resolve weaknesses in the Air Monitoring Program such as (1) insufficient frequency of particulate air samples to evaluate short-term transients and periodic events, and (2) inadequate equipment and/or programs to detect airborne tritium conceritrations in excess of 0.1 of the Derived Air Concentration (DAC) promptiy to comply with the Order requirements to post :entrances to such areas as Airborne Radioactivity Areas.

The contractor has committed to the following actions to provide timely detection and evaluation of airborne radioactive material:

1. Particulate Air Sampling - In WSRC letter ESH-HPC-910072, "K-Reactor Workplace Air Monitoring SER Item \#8", dated March 14, 1991, the contractor details their program for particulate air sampling to evaluate short-term transients and periodic events. Specifically:

a. Particulate air sampling will be performed on a routine bas is using portable air samplers to obtain grab samples prior to and/or during high airborne potential jobs such as line breaks, cutting, grinding, etc.

b. Placement of beta-gamma constant air monitors (CAMs) at strategic locations or jobs to provide alarm capability for airborne particulate radioactive material.

2. Tritium - The contractor committed to the following actions in SRS-DOE-5480.11-CSA-41, "Radiation Protection for Occupational Workers", Revision 3, dated August 5, 1991:

a. Continue the use of the existing Kanne systems which can detect $1 \times 10^{-5} \mathrm{uCi} / \mathrm{cc}$ tritium (50 percent of the DAC $1 \mathrm{imit}$ ).

b. Intensify the present silica gel sampling program as defined in procedure 5Q1.5-230, "Silica Gel Grab Sampling for the 100 Area Reactors", Revision 0, dated March 18, 1991, to characterize facility airborne tritium activity and document the locations and conditions where 0.1 DAC may be likely.

c. Procure and evaluate state-of-the-art, commercially available tritium monitors to determine if these monitors provide improved detection capabilities over the present Kanne ion chambers.

d. Evaluate a low range picoammeter with a Kanne ionization chamber to determine if improved sensitivity can be achieved under field conditions.

Based on a DOE review of the above documentation and on the contractor's commitments in CSA-41, approved by DOE on October 3, 1991, this item is closed.

There are five open items remaining to be resolved for this issue. 


\subsection{Unreviewed Safety Questions (USQS)}

Open Item: The WSRC USQ procedure does not consider new analyses or findings, which reveal previously unrecogrized hazards to the safety of the reactors.

Site-wide and reactor restart procedures, i.e., the 110 Manual, "Westinghouse Administrative and Procedural Controls System for SRS Reactors and Non-Rector Nuclear Facilities," Section 2.01, "Unreviewed Safety Question Procedure," Revision 1, effective September 9, 1991, and the RD-1 Manual, "Reactor Restart Division Administrative Manual," Section RDP-12.03, "Unreviewed Safety Question Screening and Evaluation Procedure, "Revision 1, effective August 1, 1991, respectively, have bzen revised, and issued, to incorporate addressing by the USQ process new information adverse to the design basis. The K-Reactor Administrative Control Technical Specifications, Revision 3, approved by DOE on August 22, 1991, reflect this. The site-wide procedures apply to al1 divisions within WSRC working on reactor-related tasks. Therefore, this item is closed.

All open items have been resolved for this issue. 


\subsection{Technical Baseline Program}

Open Item: Completion of the WSRC surveillance of the Technical Baseline Program (TBP), and DOE review for adequacy.

The DOE staff reviewed the WSRC Reactor Quality Department (RQD) Document Review Forms QRC-89-371 RRD-QA, "Document Review Form," dated July 14, 1989, and QRC 89-378 RRD-QA, "Document Review Form," dated July 20, 1989, both of which documented quality reviews of five draft Technical Basel ine Documents. The scope of the reviews was directed to assuring compliance with the TPP Writer's Guide, which provides the requirements and format for information to be included in the Technical Baseline Documents. A sample of the RQD comments was selected, and the affected final Technical Baseline Document was reviewed to verify incorporation of the comments. The review found that the RQD commerits were incorporated into the final documents in accordance with the applicable comment disposition. Although no evidence of RQD acceptance of the comment dispositions was available on the review forms, subsequent reverifications performed by the DOE staff found that the comments were accepted by the RQD staff and were documented according to the applicable procedure.

The DOE staff reviewed Reactor Quality Verification (RQV) Surveillance Report 90-SUR-02-012B RRD-QA, "Surveillance Report," dated August 10, 1990, which documents a surveillance of the information management practices of the Reactor Engineering Technical Baseline Program. No deviations were reported from the surveillance.

The DOE staff review found that another surveillance of TBP practices was conducted by Reactor Quality Assurance from July 20, 1990 through August 2, 1990, and is documented in Surveillance Report 90-S-02R-156 RRD-QA, "Surveillance Report," dated August 6, 1990. The surveillance was conducted to verify that critical components identified on the lists can be physically ident ified. Five deviations were identified. Reactor Engineering responses to the findings were reviewed and found acceptable.

DOE review of the above surveillances by WSRC of the Restart Technical Baseline Program activities finds that adequate quality program monitoring was provided to assure compliance with program procedures. Therefore, this item is closed.

There are two open items remaining to be resolved for this issue. 


\subsection{Design Change Process}

Open Item: To address qualifications of personnel performing formal design review, issue the "Desk Top Instructions," or its equivalent, as a final document.

WSRC has implemented the use of RP-5.1110, "System Cognizant Engineering," Revision 0, dated July 29, 1991. In this procedure it is clearly stated that the cognizant system engineer initiates or at a minimum participates in the design and implementation of design changes and modifications for the system(s) assigned to him. Chapter 4.3 of this procedure tasks the cognizant engineer with specific design authority duties and responsibilities, and defines design authority as "the organization responsible for final approval of designs." Attachment B of this procedure specifically outlines minimum qual ifications for cognizant system engineers. Further, INPO Guideline 85-031, "Guidelines for the Conduct of Technical Support Activities at Nuclear Power Facilities" and INPO Good Practices TS-413, 85-033, "Use of System Engineers" were used in the preparation of this procedure making this procedure comparable to those procedures utilized in commercial nuclear facilities. This item is closed.

Open Item: Specific provision for an "independent multi-discipline" review of lower level "operating expense" projects has not been made.

The flow of design change data, as defined in RDP 5.01, "Reactor Plant Modification and Design Control Program," Revision 0, dated December 10, 1990, for the Reactor Restart Division (RRD), provides for the use of the WSRC Engineering and Projects Division (E\&PD) as the sole design agent for operating expense projects. E\&PD-DP-320, "Design Verification," Revision 1, dated May 21, 1991, governs the review process by which design changes are verified by the E\&PD.

Upon receipt of the design inputs as defined by RDP 5.01, the E\&PD Manager of Project Engineering assigns cognizance for the design change to a Discipline Engineering Manager (DEM). This DEM is assigned the responsibility by E\&PD, DP-320, for the selection of the appropriate method of design verification. C\&PD-DP-320 also makes specific provisions for the selection of a design verifier, to assure the independence of the design verification process. The verifier, at a minimum, will have the same qualifications as the designer and shall not have performed the actual design. The identification of the impacted departments/disciplines, whose reviews are required for a multidiscipline review, is made by the cognizant DEM during the initial screening process of the design inputs from the RRD. As a check on the correctness of the identification made by the cognizant DEM, the design change must also be reviewed by the cognizant system engineer and the Manager of Project Engineering. These verifications are documented by signature on the design change form which is maintained by E\&PD in accordance with the provisions of Section 6.0 of E\&PD-DP-320.

RP 5.1301, "Technical Review of Modifications," Revision 0, dated September 6, 1991, has recently been implemented by WSRC, and works in conjunction with E\&PD-DP-320. RP 5.1301 establishes the requirement for a 
multidiscipline/interdepartmental review for both permanent and temporary modifications. RP 5.1301 requires the "Modification Engineer" to identify and distribute modification packages to impacted departments/disciplines for their review, and further requires the "Modification Engineer" to take the lead in comment resolution, prior to the submission of the change package to the "Design Authority Engineer." The generated review documentation is included and retained with the modification package.

By defining E\&PD as the sole design agent for operating expense projects, and implementing E\&PD-DP-320 and RP 5.1301, WSRC has provided for an independent multi-discipline review of operating expense projects. Therefore, this item is closed.

There are two open items remaining to be resolved for this issue. 


\subsection{Software Quality Assurance (SQA)}

Open Item: Completion of DOE review and acceptance of a WSRC exemption request regarding the verification and validation (V\&V) of codes to fully support the Safety Analysis Report (SAR) and the Probabilistic Risk Assessment (PRA).

The DOE staff reviewed the subject WS:C exemption request, \#90-ER-003, submitted by letter dated October 22, 1990. In response to the staff's review, WSRC submitted a revised exemption request by letter dated May 8 , 1991, "Resubmittal of Quality Assurance (QA) Exemption Request \#90-ER-003, Revision 1." The DOE staff reviewed the revised exemption request and concurs that the exemption is necessary to support the use of SAR and PRA codes, provided the codes are frozen in their present forms until they are fully certified, currentiy scheduled for September 30, 1992. The staff determined that the compensatory measures, i.e., documenting code descriptions, certification status, interim configuration control, critical parameter justification (demonstration of confidence), and code benchmarking, are acceptable. DOE approved the revised exemption request by letter to WSRC dated June 27, 1991, "Resubmittal of Quality Assurance (QA) Exemption Request \#90-ER-003, Revision 1 (Letter, P. W. Dickson to F. R. McCoy, 5-8-91). "The DOE staff concludes that the revised exemption request, together with WSRC-RP-90-433, "Verification and Validation Plan for Safety and PRA Codes," Revision 1, dated March 1991, WSRC-TR-90-183, "Certification Plan for Safety and PRA Codes," Revision 1, dated March 1991, and WSRC Procedure Manual 1Q35, "Safety Analysis and Risk Management (SA\&RM) Quality Assurance Procedures," Procedure 1.13, "Software Development and Control," Revision 0, effective September 18, 1990, adequately address V\&V and certification of SAR and PRA codes for restart. Therefore, this item is closed.

Open Item: The Certification Plan for Reactor Analys is Computer Codes does not address code re-certification when updates are made to the codes.

The DOE staff reviewed the WSRC method of SQA control for modified software, submitted by letter dated June 7, 1991, "Recertification of Modified Software, SER 5.8." The method relies on the implementation of the WSRC Quality Assurance (QA) Manual, 1Q, which is ongoing and currently scheduled to be completed for the WSRC Reactor Restart Division in March 1992. In accordance with QA Manual 1Q, Procedure QAP 20-1, "Software Quality Assurance," Revision 1, effective October 1, 1990, certification of a new version of a code will include successful completion of a defined set of controlled test problems. The set of required test problems will vary with the extent of the software modification being implemented by the version change. This approach to recertification of modified software will be implemented as the code Certification Plan is implemented. The DOE staff finds this approach acceptable for addressing code recertification. This item is closed.

Open Item: The V\&V plan lacks the necessary measures for corrective actions once deficiencies are identified during V\&V. 
Attached to WSRC letter dated June 7, 1991, "Recertification of Modified Software, SER 5.8," is a WSRC/SRL Inter-0ffice Memorandum, SRL-RQP-91-1108, dated May 30, 1991, stating that all modifications to software for which a baseline was established and any new software used in high impact "critical" analysis shall conform to the WSRC software QA program, i.e., the requirements of WSRC QA Manual 1Q. Procedure QAP 20-1 of WSRC QA Manual 1Q addresses measures for corrective actions once code deficiencies are identified during verification testing, and states that "Test problems shall be developed, conducted, and documented to permit confirmation of acceptable performance of the computer program before it is used in the operational system." Therefore, this item is closed.

Open Item: Since the draft V\&V and Certification plans for SAR and PRA codes show a completion date beyond restart, an exemption request must be submitted.

WSRC addressed this item is a revision to exemption request \#90-ER-003, submitted by letter dated May 8, 1991, "Resubmittal of QA Exemption Request \#90-ER-003, Revision 1." The DOE staff reviewed the compensatory measures identified in the revised exemption request, i.e., documenting code descriptions, certification status, interim configuration control, critical parameter justification (demonstration of confidence), and code benchmarking, and determined that they are acceptable for restart. DOE approved the revised exemption request by letter to WSRC dated June 27, 1991, "Resubmittal of Quality . ssurance (QA) Exemption Request \#90-ER-003, Revision 1 (Letter, P. W. Di kson to F. R. McCoy, 5-8-91)." This item is, therefore, closed.

Open Item: Provide a demonstration of confidence for the SAR and PRA codes.

WSRC provided a demonstration of confidence for the SAR and PRA codes in a revision to exemption request \#90-ER-003, submitted by letter dated May 8, 1991, "Resubmittal of QA Exemption Request \#90-ER-003, Revision 1." The demonstration of confidence was addressed by a critical parameter justification, which included a description of the major code inputs to various codes and the methodology for choosing their input value, and the method for ensuring valid results. Input values are evaluated and chosen based on guidelines contained in the Nuclear Regulatory Commission's NUREG0800, "Standard Revision Plan for the Review of Safety Analys is Reports for Nuclear Power Plants." Additionally, the computer codes are either standard codes widely accepted and used by the nuclear industry or are codes developed at SRS. Examples of the standard industry codes are the sequence of PRA codes and the major reactor safety codes. The DOE staff review determined that the critical parameter justification provides an adequate demonstration of confidence for the SAR and PRA codes. DOE approved the revised exemption request by letter to WSRC dated June 27, 1991, "Resubmittal of Quality Assurance (QA) Exemption Request \#90-ER-003, Revision 1 (Letter, P. W. Dickson to F. R. McCoy, 5-8-91)." This item is closed.

Open Item: In lieu of full configuration control, submit an exemption request that addresses short-term deviations and compensatory actions for configuration control. 
WSRC addressed this item by exemption request \#90-ER-001, submitted by letter dated May 23, 1990, and in Revision 1 to exemption request \#90-ER-003, submitted by letter dated May 8, 1991, "Resubmittal of Quality assurance (QA) Exemption Request \#90-ER-003, Revision 1." The D0E staff reviewed the shortterm deviations and compensatory actions for configuration control, which include controls described in WSRC Procedure Manual 1Q35, Procedure 1.13, and various Nuclear Reactor Technology and Scientific Computations (NRTSC) procedures. Also, the DOE staff reviewed software configuration control for the MARY non-LOCA transient safety analysis code to verify compliance with ASME NQA-1 Supplement 35-1 for design control and ANSI/ASME NQA 2.7, "Quality Assurance Requirements of Computer Software for Nuclear Facility Applications." The staff's review determined that the exemption requests adequately address short-term deviations and compensatory actions for configuration control. DOE approved exemption request \#90-ER-001 by letter to WSRC dated July 1i, 1990, "Quality Assurance (QA) Exemption Request \#90-ER-001," and Revision 1 to exemption request \#90-ER-003 by letter to WSRC dated June 27, 1991, "Resubmittal of Quality Assurance (QA) Exemption Request \#90-ER-003, Revision 1 (Letter, P. W. Dickson to F. R. McCoy, 5-8-91)." Therefore, this item is closed.

Open Item: The existing Nuclear Reactor Technology and Scientific Computations (NRTSC) QA procedures do not fully address the control of code output, and site-wide the control of code output is inconsistently practiced, since no formal procedure exists, and there is no facility to provide controlled/retrievable $Q A$ record storage for code output.

A WSRC task team, consisting of representatives from the Savannah River Laboratory (SRL), the Reactor Engineering Department, and Information Record Management, developed short-term and long-term strategies to address this item. These strategies are described in a March 11, 1991 letter from WSRC, "Code Output Control and Error Reporting." The short-term solution involves use of the Non-Conformance Reporting (NCR) System for error tracking of critical analysis codes, and the use of plant internal and retention databases for output control and retrieval. The Design Parameter Working Group, which consists of representatives responsible for the overall reactor analysis functions, will evaluate the errors reported through the NCR System for their impacts and for adequate corrective actions. Additionally, WSRC committed to evaluate long-term solutions to site-wide control of code output post-restart. Based on its review, the DOE staff concluded that the short-term solution described in the WSRC letter of March 11, 1991 was adequate to address this item for restart. DOE approved the short-term and long-term strategies by letter to WSRC dated July 1, 1991, "Safety Evaluation Report (SER), Section 5.8, Open Item 6. Strategies for Software Procurement, Code Output Control, and Error Reporting." In its approval letter, DOE requested that the longterm solution shall be an appropriate subject for deliberation by the Savannah River Site Computing Counci1, described in a March 5, 1991 letter from WSRC to DOE, "SER 5.8 Open Item 6, Strategies for Software Procurement." This item is closed.

Open Item: Provide the completed engineering software procurement management strategy for DOE review and approval. 
WSRC provided the strategy for software procurement management by letter to DOE dated March 5, 1991, "SER 5.8 Open Item 6, Strategies for Software Procurement." The short-term solution requires that all software procurement for scientific and engineering use be reviewed by the SRL Nuclear Reactor and Scientific Computation Section for compliance with software management requirements. The long-term solution is the establishment of the Savannah River Site Computing Council to set site policy on computing matters. Based on its review, the DOE staff determined that the short-term solution is adequate for restart. DOE also endorsed the formation of a Computing Council and concurred with the high priority schedule for that group to provide the first set of site standards for critical (safety-related) software support by the end of 1991. DOE approved the short-term and long-term software procurement management strategies by letter to WSRC dated July 1, 1991, "Safety Evaluation Report (SER), Section 5.8, Open Item 6, Strategies for Software Procurement, Code Output Control, and Error Reporting." Therefore, this item is closed.

A11 open items have been resolved for this issue. 


\subsection{Seismic}

Open Item: Field investigation on the SRS must be continued as part of the effort to further confirm that the Pen Bran in Fault is not a capable fault.

As discussed in the SER, a variety of geologic field investigations have occurred to determine the location and age of last movement for the Pen Branch Fault (PBF) on the SRS. Evidence suggests that the fault is not capable. To address the remaining uncertainty regarding the age of last movement, field investigations were undertaken by Westinghouse to confirm that the PBF is not a capable fault. These studies included the continued evaluation of borehole information (core inspection and geophysical logging), the completion of a high resolution seismic reflection survey specifically planned to investigate the PBF, and the reprocessing of deeper seismic reflection data. The results of these detailed studies are described in: (1) WSRC-TR-91-87, "Pen Branch Fault Program: Consolidated Report on the Seismic Reflection Surveys and the Sinallow Drilling (U)," dated March 15, 1991; (2) WSRC-RP-90-987, "Classification of Hydrostratigraphic Units at Savannah River Site, South Carolina," dated 1990; and (3) "High Resolution Seismic Survey Pen Branch Fault Savannah River Site, South Carolina," Emerald Exploration Consultants, in. Contract Number AA2027S, dated April 1991. DOE has reviewed these studies and reached the following conclusions.

0 Interpretation of borehole information supports the identification and location of the PBF. A number of stratigraphic units shon' a reversal of dip, providing evidence for deformation; the location of this deformation coincides with the location of the PBF. The extent (age of last movement) and origin (faulting versus non-tectonic) of the deformation is uncertain due to the spacing of the boreholes, which is several thousand feet. It is assumed, however, that the deformation is associated with faulting on the PBF. Interpretation of borehole information for the very shallow units suggest that the deformation is not present and that these units are flat lying in the area of the PBF. This suggests that the deformation ceased by the time that these units were deposiced. The age of these units is thought to be at least 5 million years old. The primary uncertainty associated with this conclusion pertains to the resolution capability associated with the borehole spacing and the accuracy of the shallow geophysical logging information.

- The shallow seismic reflection survey has provided very high quality geophysical information for the upper 1000 feet over the PBF. Interpretation of the shallow reflection data includes the identification of $f_{a-i t}$ ing at depth, deformation in the forming of layer draping, and no deformation in the shallowest material above a depth of about 200 feet. The pattern of deformation is generally consistent from reflection line to line, and the location of the PBF is consistent with the location identified by earlier deeper seismic reflection data. The interpretation of the shallow seismic reflection data is qualitatively consistent with the borehole data given the uncertainties associated 
with the data spacing and processing for each of the techniques. The evidence from the shillow reflection data suggests that PBF deformation ceased several million years ago.

- Reprocessing of deeper seismic reflection data is proceeding. Current unpublished results, reviewed at the contractors office, supports the above discussion that the PBF deformation is decreasing towards the surface, and that the fault has not had any movement for several million years.

The above statements all support the conclusion that the shallowest geologic material (upper 100-200 feet) shows little, if any, deformation. This must be viewed in the context of the uncertainties in the individual techniques with respect to their resolution capabilities. One important conclusion is that multiple techniques tend to suggest a similar interpretation, even though the details of the individual interpretations may differ. Additionally, the deformation that is observed is relatively minor (tens of feet) in material that is tens of millions of years old, suggesting that the rate of deformation is extremely low. Finally, evidence suggests that the PBF deformation ceased prior to the Quaternary (about 2 million years ago). This supports the conclusion that the PBF is not a capable fault.

The DOE Office of New Production Reactor, in coordination with the office of Defense Programs, is supporting an effort to perform a detailed drilling program in a location where there are existing boreholes, deep reflection data, and shalluw reflection data. The detailed drilling information will directly correlate stratigraphic units to seismic reflectors. DOE will review this information to ensure that the current conclusion regarding the PBF is consistent with any new information.

Based on the above assessment, DOE concludes that the Pen Branch Fault is not capable, and that this item is closed.

Open Item: Development of site-specific deterministic estimates of ground motion to confirm the appropriateness of the Design Basis Earthquake (DBE).

As discussed in the SER, WSRC undertook a study to assess vibratory ground motion that would include site-specific deterministic estimates of ground motion for both the Coastal Plain seismic source and the Charliston seismic source, following the approaches defined in the U.S. Nuclear Regulatory Commission (NRC) Standard Review Plan (SRP), Section 2.5.2. In parallel to this effort, DOE requested that their consultants, Brookhaven National Lab, providr estimates of potential site-specific ground motion effects to compare agains: the work of WSRC. These studies were completed and are reported in: (1) WSRC-TR-91-124, "Savannah River Site Design Basis Earthquake and Associated Strong Ground Motions," Revision 1, dated March 21, 1991, with attachment: "Final Report Ground Motion Following Selection of SRS Design Basis Earthquake and Associated Deterministic Approach," Geomatrix Consultants, WSRC Subcontract AA202loS, dated March 1991; and (2) "Site Specific Estimates of Surface Ground Motions for the K-Reactor Site Savannah 
River Plant," Report No. CEERC-91-003, Prepared by the Earthquake Research Center, Department of Civil Engineering, City College of New York, dated March 1991. DOE has reviewed these studies and reached the following conclusions:

$0 \quad$ The earthquake magnitude and distance associated with the Coastal Plain seismic source and the Charleston seismic source are appropriate and conservative. The specific values are $M=5.0\left(m_{b}=5.25\right)$, distance $=$ 9.5 miles (15 kilnmeters) for the Coastal Plain source, and $M=7.5$, distance $=70 \mathrm{miles}(110 \mathrm{kilometers})$ for the Charleston source. These values are consistent with those described in the SER, are consistent with the values approved by the NRC for the Vogtle reactor, and meet the criteria identified in the NRC SRP.

0 The methods used to calculate vibratory ground motion are appropriate and conservative, and meet the criteria identified in the NRC SRP. Several methods were used to estimate peak ground acceleration and response spectra. These methods included the development of sitespecific spectra using an approoriate set of strong motion records, the use of published attenuation relaiionships, and direct estimation using mathematical models of the source and propagation effects.

- The modification of vibratory ground motion through the deep soil at the Savannah River Site has been adequately quantified and assessed. In general, ground motion for frequencies above about 4 hertz will be attenuated, while lower frequencies will be amplified. The results presented in the studies are generally consistent, including the potential effects of high frequency ground motion that may be associated with Eastern United States earthquakes.

- Response spectra generated in WSRC-TR-91-124 were compared to the DBE response spectra a Regulatory Guide 1.60 spectra anchored to a peak ground acceleration of $0.20 \mathrm{~g}$. In making this comparison, DOE reviewed the approaches that the NRC has used to evaluate older reactor facilities for potential seismic motions. The NRC's Systematic Evaluation Program established criteria for 01 der reactors for deterministic ground motions. The NRC criteria was that the DBE spectra should not fall below the median deterministic ground motion spectra. DOE considers that this approach is valid and conservative for the $\mathrm{K}$-Reactor. The DBE spectra was found to be conservative when compared to the median deterministic ground motion spectra.

- Deterministic spectra at the median plus one standard deviation (84th percentile) would be used for new reactors, consistent with the NRC SRP. DOE compared the 84th percentile from WSRC-TR-91-124, and found that the exceedances were relatively minor, generally for frequencies above 15 hertz. The K-Reactor DBE spectra was also compared to the population of commercial reactors in terms of the probability of exceeding the Safe Shutdown Earthquake (SSE) response spectra. It was found that the probability of exceeding the K-Reactor DBE was not an outlier when compared to the commercial reactors ( $K$-Reactor was about in the middle of the data set for probability of exceeding the DBE or SSE). This further supports the conservatism of the K-Reactor DBE spectra. 
Questions have also been raised regarding the preliminary Design Basis response spectra that has been associated with the New Production Reactor (NPR) at the Savannah River Site. This spectra is a modified Newmark-Hall response spectra anchored to a peak ground acceleration of $0.30 \mathrm{~g}$. Compared to the K-Reactor response spectra, the NPR spectra is higher for frequencies above about 2 hertz. Several reasons exist to justify a higher DBE spectra for the NPR. First, the NPR spectra should envelope deterministic spectra (for the basement rock site conditions at the NPR site which are different than the K-Reactor site) at the 84 th percentile, consistent with a new reactor, as discussed above. Second, the cost associated with a more conservative seismic design can be minimized if factored into the design early, particularly for ground motions associated with the Eastern United States. Third, a decision was made to ensure that the probability of exceeding the NPR spectra was conservative when compared to the population of reactors, in terms of the probability of exceeding their SSE'S. DOE continues to coordinate efforts between the seismic assessment of K-Reactor, and the seismic work being completed for the NPR, to ensure that any significant findings are factored into the seismic safety assessments.

DOE is actively developing specific seismic requirements for all DOE facilities, including reactors. Current DOE requirements are contained in DOE Orders 5480.6 and $6430.1 \mathrm{~A}$, and implementing references including UCRL-15910, "Design and Evaluation Guidelines for DOE Facilities Subjected to Natural Phenomena Hazards". In general, the approach outlined in UCRL-15910 is a graded approach with more stringent seismic standards for the more hazardous facilities. The seismic assessment for K-Reactor has generally followed approaches developed by the NRC for reactors, including techniques for evaluating older reactors, and results in a seismic assessment that is more conservative than the techniques described in UCRL-15910 for High Hazard DOE facilities. As DOE continues to develop seismic standards, these standards will be reviewed to determine if changes need to be made regarding the seismic evaluation for K-Reactor.

Based on the above assessment, DOE concludes that the $K$-Reactor DBE is adequate and conservative, and that this item is closed.

Open Item: Demonstrate that the floor frequencies of the reactor building are sufficiently high to ensure that the structural amplifications of the vertical motion are no larger than structural amplifications of the horizontal motion.

The vertical floor response spectra in K-Reactor was assumed to be two thirds of the horizontal spectra. The preliminary basis of this assumption was a comparison of the vertical to horizontal ratios of free field motion, soilstructure interaction (SSI) parameters, and structural amplification. An open item was retained to demonstrate that the vertical frequencies of the floor slabs are more than the primary structural frequencies (required if the structural amplifications are to be less than the horizontal structural amplifications).

WSRC reviewed this concern and the results are reported in WSRC-RP-90-1328, "Evaluation of 105-K-Reactor Building Floor Slab Frequencies and Basemat Stresses," dated June 1991. All floor slabs having restart equipment (floors 
between the minus 20-foot elevation and the 34-foot elevation) were reviewed. The slabs were loaded with dead load, 30 psf live load, and a .2G seismic load based on dead weight and the live load. The maximum bending stress was found to be $394 \mathrm{psi}$, as compared with a modulus of rupture of 410 psi (based on core tests which indicate a concrete strength of at least 3000 psi). It was, therefore, concluded that the slabs remain uncracked. Frequencies were then calculated for uncracked slabs using boundary conditions consistent with the reinforcement details. Sixty-three slab segments were investigated and only 14 segments had frequencies less than $33 \mathrm{cps}$ with the lowest being $14.6 \mathrm{cps}$ (only 2 segments have frequencies less than $16 \mathrm{cps}$ ). However, slabs having the frequencies less than $33 \mathrm{cps}$ were found to be either roof slabs or slabs that support no restart equipment.

Based on these results and a comparison with the global structural frequencies, it can be concluded that vertical structural amplifications will be less than horizontal structural amplifications. This item is, therefore, closed.

Open Item: The floor slabs and foundation basemat in the reactor building must be evaluated for the seismic load case.

Recent work performed by WSRC, documented in WSRC-RP-90-1328, "Evaluation of 105-K-Reactor Building Floor S1ab Frequencies and Basemat Stresses, "dated June 1991, addresses this item. During the evaluation of the vertical floor response spectra, the peak stress in the critical floor slabs was evaluated to be $394 \mathrm{psi}$ (assuming uncracked sections) for a combination of dead, live, and seismic loading. This indicates that stresses in the floor slabs are below the modulus of rupture and remain uncracked.

Stresses in the K-Reactor basemat were also evaluated. Bearing pressures were evaluated for dead load, a 100 psf live load, and the DBE considering the basemat to be rigid and including the effects of eccentricities in the mass distribution of the building. The peak bearing pressure was evaluated as $11.94 \mathrm{ksf}$, and it was demonstrated that liftoff would not occur. This peak bearing pressure was applied to the entire basemat and stresses evaluated at the critical sections. The maximum demand/capacity ratio was found to be 0.71 for moment and .70 for shear. Based on these results, this item is closed.

Open Item: Finalize and issue for DOE review the United Engineers and Constructors (UE\&C) report on the analys is of the Supplementary Safety System (SSS) piping.

The UE\&C report UE\&C 8244.623-S-M-001-F, Supplementary Safety System Piping Analys is Reconciliation, was issued as a final report in July 1990, and has been reviewed by the DOE staff. This item is closed.

Open Item: Satisfactory resolution of all observations requiring action and categorized as startup items in the Screening and Evaluation Worksheets (SEWs) resulting from the walkdowns of SSS. 
The SEWs resulting from the walkdowns contained observations which required corrective actions, and identified installation modifications which needed to be completed for restart. These necessary corrective actions have been completed, as documented in WSRC correspondence EPD-SE-91-0026:68 of January 25, 1991, and RRD-RRP-910025 of January 30, 1991. Therefore, this item is closed.

Open Item: Resolve the overstress issue for the cooling water supply line due to the effect of heat exchanger flexibility.

Confirmatory analysis performed by the DOE staff showed portions of the cooling water line to be overstressed. A more refined analys is performed by WSRC has demonstrated that this line is not overstressed. The analyses are contained in WSRC report EPD-SE-91-0024, SRS K-Reactor Piping Analysis Report for the Process Water, Diesel Power, and Cooling Water Systems for Lines K-CWS-23-05 and 06, Revision 0, dated January 17, 1991. The DOE staff has reviewed these analyses and agrees with the conclusions. This item is, therefore, closed.

Open Item: Address the adequacy of four CWS piping supports when friction loads due to seismic loading are considered.

The adequacy of four CWS supports due to the effect of friction loads was questioned. WSRC calculations were updated to include the effects of seismic friction loads on the supports and the results are acceptable. This analysis is contained in the Westinghouse report EPD-SE-91-0024, SRS K-Reactor Piping Analys is Report for the Process Water, Diesel Power, and Cooling Water Systems for Lines K-CWS-23-05 and 06, Revision 0, dated January 17, 1991. The DOE staff has reviewed the calculations and agrees that these supports are arceptable. Therefore, this item is closed.

Open Item: In the analysis of the buried piping in the Contaminated Water Removal and Disposal System (CWRDS), consider the effect of compression, shear, and Rayleigh waves acting simultaneously.

The Blume analysis for the buried piping left questions concerning wave passage effects on the buried piping. WSRC has prepared a supplementary report which demonstrates the adequacy of the buried piping. This analysis, contained in report WSRC-RP-90-1346, "Report on Qualification of Buried Piping for the K Area", dated December 19, 1990, demonstrates that the assumptions made in considering wave passage effects were conservative. The DOE staff has reviewed this report and agrees with its conclusions. This item is closed.

Open Item: Document the final results of the DOE staff's analysis of the seismic adequacy of the reactor internals.

A confirmatory analysis was performed by the DOE staff to address the adequacy of the reactor internals. This analysis indicates that the reactor internals satisfy the SER restart criteria. This analysis is contained in the Brookhaven report SAD-90-100, "Savannah River K-Reactor Mark 22 Fuel and Target Assembly Seismic Adequacy Evaluation," dated August 1990. This item is closed. 
Open Item: Document the results of the DOE staff's confirmatory analysis of the seismic adequacy of the reactor supports.

A confirmatory analysis was performed by the DOE staff to address the adequacy of the reactor supports. This analysis indicates tr; the reactor supports satisfy the SER restart criteria. This analysis is contained in the DOE staff report, RLCA/P191/01-90/001, "Seismic Analys is of Selected K-Reactor PWS Equipment," dated August 24, 1990. This item is closed.

Open Item: Document the results of the DOE staff's confirmatory analysis of the seismic adequacy of the reactor tank expansion ring.

A confirmatory analysis was performed by the DOE staff to address the adequacy of the reactor tank expansion ring. This analys is indicates that the reactor tank expansion ring satisfies the SER restart criteria. This analysis is contained in the DOE staff report RLCA/P191/01-90/001, "Seismic Analysis of Selected K-Reactor PWS Equipment," dated August 24, 1990. This item is closed.

Open Item: Confirm the similarities in the suction line piping configurations for all six Bingham pumps in the PWS.

Although the Blume analysis qualified all of the suction lines based upon similarity, the similarity in loading was not demonstrated. WSRC has prepared an assessment of the similarity of the suction lines. This analys is is documented in the WSRC memoranda EPD-SE-91-0014:68, "DOE SER \#34 PWS Pump Suction Line Similarities", of January 10, 1991, and EPD-SE-91-0090:68, "Seismic SER Open 1tem Nos. 34, 35 and 36 Section 6.1" of March 13, 1991. This subsequent analysis compared the unanalyzed 1 ines to 1 ines that had been analyzed and found that the loads from the analyzed lines represented the worst case condition. The DOE staff has reviewed this documentation and determined that it adequately addresses the similarity issue. Therefore, this item is closed.

Open Item: Complete the seven required construction modifications identified in the Bingham pump SEWS, "Modified NCR Forms."

Construction and installation modifications were identified in the SEWs. These modifications have been made as part of K-Reactor Restart Project 2934. Documentation for these modifications is provided in WSRC Memorandum RRD-RRP-910089, Seismic SER Items, dated March 22, 1991. This item is closed.

Open Item: Provide additional justification to demonstrate seismic adequacy of the diesel fuel oil tank for the Recirculation Pump Emergency Diesel Generator System.

The qualification analysis for the diesel fuel oil tank has been supported by WSRC memorandum EPD-SE-91-0062:68, "DOE SER Seismic Open Item 27, " of March 1, 1991. The DOE staff has reviewed this analysis and found that it satisfactorily addresses the open item. Therefore, this item is closed. 
Open Item: Demonstrate the adequacy of the exhaust silencer mounting and the enclosure/beam connection for the Recirculation Pump Emergency Diese 1 Generator System.

The exhaust silencer to roof beam. connection details were previously not analyzed as part of the seismic qualification. WSRC provided an analysis of this detail in WSRC Memorandum EPD-SE-91-0062:68, "DOE SER Seismic Open Item 27," of March 1, 1991. The DOE staff has reviewed this analys is and found it to be acceptable. This item is closed.

Open Item: Resolve the overstress of the vertical guide supports on the PWS piping at the minus 20-foot elevation, and address the issue that existing gaps in several guides make them inactive as seismic supports.

The DOE staff performed additional analysis to determine the effect on the PWS if the guide supports were inactive. This analysis, contained in RLCA Topical Report P191/01-90/002, "K-Reactor PWS Piping and Support Confirmatory Analyses," dated August 24, 1990, verified that the vericical guide supports were not required for the PWs to meet acceptance criteria and that the supports were redundant. However, in allowing the vertical guide supports to be overstressed, there was a concern that there may be seismic interaction effects (II/I) which would pose a risk to the system. In order to address the issue of seismic interaction effects, WSRC with DOE staff performed a seismic walkdown of the vertical guide supports to determine any II/I problems that may occur. The walkdown noted that total support collapse could pose a threat to small piping lines essential to the operation of the PWS pumps. WSRC then performed analysis on the guide supports to demonstrate that the supports would maintain their structural integrity under DBE conditions. WSRC report SE-91-051:68, "PWS Loop Guide Supports," dated July 25, 1991, documents the walkdowns and supplementary analysis. This item is closed.

Open Item: Satisfactory resolution of the UE\&C recommendations, including the support modifications and the drawing revisions, for the Near and Far Side SSS piping.

Forty-two support modifications were recommended by UE\&C. These support modifications and drawing revisions have been made, and the documentation reviewed by the DOE staff. A record of these support modifications is contained in WSRC Memorandum EPD-SE-91-0026:68, M. Barlow to A. McFarlane, "Closure of Seismic SER Items 15, 17, and 18," dated January 25, 1991. This item is closed.

Open Item: For equipment qual ified by walkdown, there is no procedure for support member qualification.

Previous efforts had been made to seismically qualify piping systems using a walkdown methodology. In review of these procedures, the DOE staff identified support member qualification and the lack of procedures as an open item. WSRC has subsequently performed analysis on all of the piping systems which require seismic qualification for restart. Therefore, a walkdown approach is no longer being used to qualify supports. This item is closed. 
Open Item: For equipment qual ified by walkdown, the methods for addressing outliers are not defined for all equipment types.

In using the methodology of the Seismic Qualification Utility Group (SQUG) Generic Implementation Procedure (GIP), WSRC did not provide an adequate methodology for addressing outliers from the experience data base. WSRC issued report EPD-SE-91-0088:58, "Seismic SER Items" on March 12, 1991 to address this issue. Although not explicitly stated in the WSRC procedures, outliers are resolved by analysis, testing, or repair/replacement. In addition, the DOE staff walkdown team reviewed the dispensation of outliers and determined that they were addressed in a conservative manner. This item is, therefore, closed.

Open Item: For equipment qual ified by walkdown, there is no comprehensive document describing and controlling changes in the Seismic Qualification Utility Group (SQUG)-type program.

The DOE staff determined that there was no comprehensive document describing and controlling changes in the SQUG program. WSRC has since issued WSRC-TR91-42-060, "K-Reactor Seismic Evaluation Methodology and Documentation," on June 20, 1991. This document provides an overall description of the qualification program and history, and documents the changes in the program. The DOE staff reviewed this report and found it to be acceptable. This item is closed.

Open Item: For equipment qualified by walkdown, relay functionality using seismic experience data base is not acceptably demonstrated.

In reviewing the SQUG-GIP and its applicability to K-Reactor, the DOE staff determined that relay functionality using seismic experience database is not acceptably demonstrated. In WSRC report EPD-SE-91-0088:68, "Seismic SER Items, " of March 12, 1991, resolution of this item is documented. Relay functionality has been demonstrated by testing at ANCO. The testing at ANCO consisted of seismic qualification tests in accordance with IEEE-344-87, "Recommended Practices for Seismic Qualification of Class 1E Equipment for Nuclear Power Generating Stations." The DOE staff reviewed the ANCO report and found that the testing program addresses the issue of relay functionality. This item is closed.

Open Item: Justification for the code allowables for SEP-24, "Verification of Seismic Adequacy of Piping Systems," Revision 2, dated December 11, 1990, and resolution of DOE comments regarding the implementation of SEP- 24 .

The WSRC methodology described in SEP-24, "Verification of Seismic Adequacy of Piping Systems," Revision 2, dated December 11, 1990, was used to analyze and seismically qualify portions of the Process Water System, Cooling Water System, and Diesel Power System. The DOE staff reviewed this methodology and found it acceptable with exceptions. One exception was the use of 2Sy as a stress allowable. WSRC has subsequently provided justification for its use. The use of alternate stress allowables has commercial precedence at the San Onofre plant using ASME Code Case $\mathbf{N}-411$. This precedent usea a strain allowable of 1 percent for carbon steel and 2 percent for stainless steel, 
which translates to a stress allowable of less than 2Sy at K-Reactor. WSRC has reviewed the caveats which were associated with this precedent and considers the K-Reactor case to satisfy them. WSRC issued Memorandum EPD-SE-91-0370:68, "SER 6.1.8.7 and 6.1.9.16 Regarding SEP-24," on

September 20, 1991 to address the issue of stress allowable. Additionally, the DOE staff had questions and comments regarding the implementation of the analytical procedures contained in an earlier version of SEP-24. WSRC has since issued Revision 2 of SEP-24, and EPD-SE-91-0024:68, "Savannah River Site $K$ Reactor Piping Analysis Report for the Process Water, Diesel Power, and Cooling Water Systems," dated January 17, 1991, which documents the analytical results using the methodology of SEP-24. The DOE staff has reviewed the revised implementation procedures and analysis, and all the comments made by the DOE staff have been addressed. This item is closed.

Open Item: Verify the as-built conditions and adequacy of the grouted "j-bolts" used on the three-way and elbow trunnion supports on the Process Water System (PWS) lines.

The seismic adequacy of the "j-bolt" support plates was originally in question due to an uncertainty regarding the as-built configuration, the quality of construction, and the failure mode of the attachment. WSRC conducted a testing and analytical program to address the questions regarding the $j$-bolt support plates. This program included destructive tests of $j$-bolt support plates in R-Reactor. These tests demonstrated the failure mode of the system and verified the construction techniques and as-built condition. There were several different plate types, i.e., 4, 6, and 8 bolt plates, which were common to both R- and K-Reactors. Concrete strength tests were performed at both $K$ - and R-Reactors to verify the consistency of materials in the two reactors and applicability of the R-Reactor tests to K-Reactor. Results of these tests with appropriate safety factors were compared to the analytical loads on the plates. The support plates were acceptable based on this analysis, or modified to be acceptable. The DOE staff has reviewed the tests and believes that the tests are directly applicable to $\mathrm{K}$-Reactor, and that the predicted capacity with safety factor is appropriate and conservative as a design allowable. Further, thorough field inspections were conducted. These inspections included ultrasonic inspections of the plates to determine the number of $j$-bolts per plate. Through this inspection, the as-built configuration of the support plates has been verified. The results of this testing, analysis, and inspection program are documented in the WSRC report WSRC-TR-91-86, "Seismic Qualification of Grouted Support Plates in 105-K Reactor Building," Revision 1, dated September 1991. This item is closed.

Open Item: Revise the SSS piping evaluations to include consideration of the thrust loads associated with system actuation.

A dynamic analysis of the SSS was performed by United Engineers and Constructors (UE\&C). This report was reviewed by the DOE staff and found to lack a consideration of the thrust loads associated with system actuation. UE\&C Final Report No. 8244-623-S-M-001-F, "Supplementary Safety System, Piping Analys is Reconciliation, K-Reactor," Volumes 1 through 10, dated July 1990, included an analysis of the hydraulic transients caused by the sudden opening of the explosive valves and the effect of those transient loads on the piping 
system. The DOE staff reviewed this analysis and questioned the time span of 0.0325 seconds that was used in the time history anaiysis. WSRC issued Memorandum EPD-SE-91-0371:68, "SSS Piping Analysis Review", on September 20, 1991, to document the resolution of this issue, and justified the time span of 0.0325 seconds used in the time history analysis. Also, an actual test of the SSS was performed in May 1991, which consisted of opening the explosive valves, with no damage to the SSS. This item is closed.

Although not associated with an open item, the following information is provided concerning the selection of systems to be seismically qualified.

The basis for selection of systems required to be seismically qualified is similar to that used by the commercial nuclear industry in addressing Unresolved Safety Issue (USI) A-46, "Seismic Qualification of Equipment in Operating Plants". This basis, developed by the Seismic Qualification Utility Group (SQUG) to address USI A-46, requires that four vital safety functions be performed. These functions, reactivity control, coolant pressure control, coolant inventory control, and decay heat removal, in addition to essential core monitoring, are needed to shutdown the reactor and maintain it in a safe shutdown condition for 72 hours following a seismic event. The systems needed to perform these functions were seismically qualified. In addition, other systems or components which may interact with the safety systems need to be seismically qualified. These resultant systems are the Supplementary Safety System, Process Water System, Cooling Water System, Diesel Power System, Moderator Recovery System, Water Removal System, and the Reactor Monitoring System.

There are nine open items remaining to be resolved for this issue. 


\subsubsection{Environmental Qualification}

Open Item: WSRC submittal of an acceptable risk-based Justification for Continued Operation (JCO).

WSRC-TR-91-42-064, "K-Reactor Restart Environmental Qualification Justification for Continued Operation Document, "Revision 1, dated July 22, 1991, with Amendment 1, dated September 9, 1991, has been reviewed by the DOE staff. This document does the following:

- Identifies the Design Basis Events (DBEs) which create bounding environmental conditions and what those bounding environments are.

o Identifies all equipment required to mitigate the bounding DBE, the functions that equipment must perform, and whether or not that equipment will be exposed to a harsh environment.

- Evaluates the required equipment to determine whether it will perform its required functions while affected by the postulated environments and provides strong technical justifications for restart based upon the functional evaluations.

o Summarizes the logic and methodology that went into evaluating and justifying plani equipment for restart.

- Identifies the incremental increase in risk incurred by starting up and operating K-Reactor with essentially unqualified equipment.

$0 \quad$ Concludes that all required safety functions will be performed and that K-Reactor can be operated safely with no adverse health or safety consequences.

The JCO is to be maintained as a living document and any changes to the design basis prior to full environmental qualification at the K-Reactor will be fully evaluated and documented. The DOE staff found the JCO to be acceptable. This item is closed.

There is one open item remaining to be resolved for this issue. 


\subsection{Sump Water Removal}

Open Item: Establish the adequacy of the Contaminated Water Removal and Disposal System (CWRDS) design based on expected leak rates following a loss-of-coolant accident (LOCA) or a seismic event.

The adequacy of the CWRDS during a LOCA or seismic event is addressed in WSRC-TR-91-83, "K-Reactor Flooding Times and Required Operator Response Times," dated March 1991, and WSRC Reactor Engineering Technical Position Paper TPP-009, "Water Removal and Storage System," dated December 1990.

Various studies were undertaken to evaluate the amount of leakage following a LOCA and seismic event. Reactor Technical Report (RTR)-2650, "Light Water Leakage Following a Design Basis Earthquake (DBE), " dated October 11, 1989, documents that the leakage induced by a seismic event would not result in a challenge to the Process Water System (PWS) DC motors. RTR-2615, "Process Water Leak Rate After a Design Basis Earthquake," dated January 23, 1989, documents that the leakage from the PWS following a DBE is within the capacity of the Moderator Recovery System and is, therefore, not a challenge to the CWRDS. SRL-NES-900047, "LOCA Throttling and Flooding Implications," dated August 13, 1990, addresses LOCA flooding analys is and emergency cooling system (ECS) throttling requirements to prevent the loss of Process Water DC motors. The steady state leak rate into the pump room is illustrated and includes the inventory of the PWS and ECS flow. For PWS pipe break LOCAs, it is procedurally allowed to throttle ECS injection. ECS throttling requirements are specified in DPSOL 105-MC-6-K, "Operation of Reactor Cooling Facilities During an Incident," Revision 19, dated September 27, 1991. The ECS throttled flow rate is less than the capacity of the CWRDS with a single failure of the largest sump pump. The result is that a pipe break LOCA is not a threat to the PWS DC motors, provided ECS throttling is properly initiated. Maintaining PWS DC motor availability assures that DC pump flow can be maintained to the reactor core to maintain cladding integrity.

WSRC-TR-91-83 documents the effects of throttling ECS flow and single sump pump failure on DC motor flood times. This study assumes the worst possible leak rate of the PWS, that being a double ended guillotine break (DEGB) of a PWS pump suction expansion joint. The study also assumes operator response to the flooding event 22 minutes following initiation of the event or when the water level in the motor rooms reaches 10 inches. The analysis was based on the ability to overcome the flooding associated with the DEGB without the loss of the PWS DC motors. The calculations were performed with and without ECS throttling and with and without single failure of the highest capacity sump pump. Further assumptions utilized in this analysis are: (1) ECS throttled flow is assumed to be $9500 \mathrm{gpm}$, and (2) motor room sump capacity of 21,992 gallons. In order to assure the motor room sumps remain free of water accumulation during rector operation, DPSOL 105-1016, "Sump Check," dated June 17,1991 , is performed just prior to reactor startup, and DPSOL 105-2302, "Removal of Water from Pumproom," dated September 28, 1991, is executed whenever water level is detected in the motor room sumps. The results of the study indicate that: (1) with no ECS throttling or pump failures, the PWS DC motors would flood in 78 minutes; (2) with no ECS throttling and single pump failure, PWS DC motors would flood in 46 minutes; (3) with ECS throttling and 
no loss of pump, PWS DC motors will not flood; and (4) with ECS throttling and single pump failure, PWS DC motors will flood in 370 minutes. Additional guidance is provided in WSRC-TR-90-352, "Guidance on Long-Term Cooling for DEBG LOCA," dated August 1990, with a conclusion that ECS throttlirg to less than $9500 \mathrm{gpm}$ is permissible. ECS minimum throttled flows are given as a function of core power level, assembly effluent temperatures, and time since event, and are procedurally controlled by DPSOL 105-MC-6-K. Throttling ECS flow, per DPSOL 105-MC-6-K, assures that PWS DC motor flooding will not occur.

The staff has determined that, based on the results documented in WSRC-TR-91-83, the issuance of the Technical Position Paper, the issuance of ECS throttling requirements and revisions to DPSOL 105-MC-6-K, and review of other associated support documents, the CWRDS is capable of tolerating the worst case flooding caused by a LOCA or a seismic event. This item is, therefore, closed.

Open Item: Complete the diversion valve redundancy study, and submit the results to DOE for review.

RTM-5029, "Reliability of Diversion Valves," dated July 19, 1991, has been completed and recommends that ACC proceduras be modified to require personnel to disable the motor room smali sump pumps, during accident conditions, if the associated diversion valves fail to divert. DPSOL 105-MC-6-K provides direction for operator action to disable the motor room small sump pumps, if the respective diversion valves fail to divert during accident conditions. The staff has reviewed RTM-5029 and concludes that the mitigating measures are adequate for restart. This item is closed.

Open Item: Complete startup testing required to demonstrate operability of the CWRDS, and provide the test results to DOE for review and approval.

The testing requirements identified in Restart Test Identification Report (RTIR) No. 7, "Water Removal and Storage System," Revision 1, dated July 11, 1991, have been successfully completed with satisfactory test results. As stated in the SER, this RTIR identifies the safety functions of the CWRDS and the required testing necessary to demonstrate equipment operability. Specific test procedures are identified in the RTIR which fulfill the required testing. Revision 1 of the RTIR was approved by the DOE Chief Test Engineer (CTE) on July 24, 1991. The testing has since been completed, and a summary of the test results is contained in Revision 2 of the RTIR. The DOE staff reviewed the completed test procedures, witnessed numerous field tests, and concluded that adequate system startup testing has been successfully completed to verify the operability of the system. The CTE approved Revision 2 of the RTIR on October 8, 1991. This item is closed.

A11 open items have been resolved for this issue. 


\subsection{Power Ascension Testing}

Open Ixem: Development of test procedures that satisfy the restart criteria, and submittal of the procedures for DOE review and approval.

The fifteen power ascension test procedures, RSP 91-007 series, the 1ast of which was approved on September 4, 1991, were reviewed and approved by DOE, and determined to satisfy the restart criteria. This item is closed.

All open items have been resolved for this issue. 


\subsection{Normal and Abnormal Operating Procedures}

Open Item: The adequacy of the individual procedures and programs listed in Attachment 2 to SER Section 10.3 has not yet been reviewed by the DOE staff.

The DOE staff reviewed procedures/procedure changes listed in Attachment 2 to SER Section 10.3 that were made in response to various ROMP commitments.

Since most of these commitments required a large number of procedure changes, the staff reviewed a sample of procedure changes to monitor compliance with the ROMP commitment. The staff reviewed procedures associated with the following ROMP items:

$$
\begin{array}{ll}
- & \text { DB-3.3 } \\
- & \text { DB-3.4 } \\
- & \text { DB-5.2 } \\
- & \text { MS-5.2 } \\
- & \text { MS-5.4 } \\
- & \text { WISRC-2.1 }
\end{array}
$$

These reviews generated only minor comments, none of which would have resulted in the applicable procedure being considered inadequate.

As part of the ongoing ROMP closure package reviews, each subject identified in Attachment 1 of SER Section 10.3 will be evaluated to ensure fulfillment of the commitment specified in the ROMP. This includes ensuring that the actions taken by WSRC to close the ROMP item are adequate for closure. Based on the procedure reviews al ready performed, and ROMP closure package reviews that will be completed prior to restart, this item is considered closed.

Open Item: WSRC does not have a formal program for tracking and reviewing commitments in procedures as a part of the revision, review, and approval process.

The restart criteria require the establishment of a progran to track operational commitments that are addressed by specific procedures to ensure that future revisions and upgrades to the procedures do not negate those commitments. RRD-ROTP-910463, Revision 0, dated May 29, 1991, addresses this issue through the identification of the operational commitments and establishment of a database. Specifically, the restart criteria from Sections 10 and 13 of the SER were reviewed and listed in a database along with the corresponding implementing procedures. DMP 7.01, "Development and Control of Reactor Operations Department Procedures, "Revision 3, approved on August 16, 1991 and effective on September 3, 1991, requires the procedure writer to review the database for the specific procedure being revised and determine if any commitments could be affected. To assist in this process, the new Conduct of Operations Manual, R 2.1, effeciive on August 1, 1991, flags all of the SER commitments at the appiicable location in the procedure to prevent these commitments from being inadvertently deleted. These actions are sufficient to address this open item. This item is, therefore, closed. 
Open Item: Establish administrative controls that define the categories of procedures and ensure that procedures are developed in all required areas.

The SER restart criteria required the establishment of procedures in a number of areas related to reactor operations. While all of the types of procedures defined in SER Section 10.3 were in place in the plant, there was no administrative procedure or other controlling document that specified the required categories of procedures for restart. This has been addressed through issuance of Revision 4 to Procedure DMP 7.01, "Development and Control of Reactor Operations Department Procedures," which was approved on September 4, 1991, with an effective date of September 9, 1991. This procedure is the controlling administrative document for Reactor Operations Department procedures. The 'Scope' section of this procedure identifies the categories of procedures and references Attachment $J$ to DMP 7.01, which gives a more detailed breakdown of the procedure categories and procedural activities. These lists contain all of the procedure types described in SER Section 10.3 with the exception of the Reactivity Manua7. The Reactivity Manual, RTR-2595, "The Reactivity Assessment Manual," is a controlled document under the auspices of the Reactor Technology Department of Reactor Engineering. As of September 23, 1991, RTR-2595 is currently at Revision 1, with an approval date of June 25,1990 . The actions taken are sufficient to address this open item. This item is closed.

Although not associated with an open item, the following information is provided concerning the incorporation of information into operating procedures.

A significant amount of technical information is generated by personnel outside the Reactor Restart Division which may affect reactor operations and procedures. To assure this information is incorporated into operating procedures in a timely manner, the process for control and incorporation of information into procedures was reviewed.

New or revised technical data can originate from various sources such as Safety Analysis Report (SAR) changes, Technical Specification changes, test results, Technical Baseline Program results, Probabilistic Risk Assessment (PRA) results, and/or Savannah River Laboratory (SRL) studies. Several methods exist to ensure the information is incorporation into operating procedures. Technical Specification change are incorporated into operating procedures in accordance with Manual 11Q, Section 2.05, "Technical Specification Revision Procedure," Revision 0, dated December 15, 1990. Changes or new information due to plant modifications are incorporated into procedures in accordance with Manual RD-1, "Reactor Administrative Manua1," RDP 5.01, "Reactor Plant Modification and Design Control Program, "Revision 0, dated December 10, 1990.

When new information is generated by SRL as a result of an experiment, safety analysis, or PRA which may impact how the reactor is operated, SRL will generate a report (called a green letter) and transmit this information to the Reactor Engineering Department (RED). This process is outlined in Manual L1, Procedure 1.22, "SRL Green Letters (Technical Recommendations) for SRS," Revision 0, effective September 16, 1991. RED evaluates the data and if 
procedure revisions are necessary, RED issues a Reactor Technology Memorandum (RTM) or Reactor Technology Procedure (RTP), in accordance with Procedure

Manual R-5.1, "Reactor Engineering Department Administrative Manual, "Section 6.1, "Reactor Technology Memorandum," Revision 0, dated November 1985, or Section 6.8, "Reactor Technology Procedure," Revision 0, dated November 1985, respectively, containing the recommendations and technical criteria for the procedure changes. This process has been evaluated by DOE as satisfactory for restart.

The process for revising the appropriate procedures, once the Reactor Training and Procedures Department receive new or revised information, is adequately described in RD 7.1, "Reactor Restart Division Procedure Writers Guide," DMP 7.01, "Development and Control of Reactor Operations, Components Handling, and Maintenance Procedures," Revision 4, dated September 4, 1991.

Due to the extensive changes to the SAR and Technical Specifications diring the restart effort, WSRC developed a program to make a final comparison of the SAR Chapter 15 parameters and assumptions, Technical Specifications requirements, parameters in Operations/Maintenance procedures, and parameters in test criteria and resolve any inconsistencies. This program is outlined in RRD-ENG-91004, Attachment 2, "Consistency Matrix Task Team Administrative Procedures," Revision 0, dated June 7, 1991.

There is one open item remaining to be resolved for this issue. 


\subsection{Emergency Operating Guidelines and Procedures}

Open Item: The Decision Point Review (DPR) documents prepared for the symptom-based Emergency Operating Procedures (EOPS) 1ack the proper controls to ensure engineering data used in the EOPS is properly maintained.

DMP 7.01, "Development and control of Reactor Operations Department Procedures," Revision 3, was approved August 16, 1991, and implemented September 3, 1991. As part of this revision, the process used to ensure adequate updating of the DPR documents was upgraded. The procedure now contains specific guidance on who is responsible for updating the DPRs and how that process is to occur. This item is ciosed.

There are two open items remaining to be resolved for this issue. 
Open Item: Development and completion of Nonconformance Report (NCR) training as delineated by ROMP HP-8.1C.

A review of the NCR training was completed in Apri1 1991. The material and conduct of the training was found acceptable. Therefore, this item is closed.

Open Item: Development and completion of training for the restart required maintenance programs, Post-Maintenance Testing and Conduct of Maintenance, as scheduled by the WSRC Maintenance Improvement Plan.

Training prior to the implementation of the Post-Maintenance test Procedure, RP-3.1003, Revision 0, approved January 9, 1991, with an effective date of Apri1 8, 1991, and the Conduct of Maintenance Procedure, RP-3.1002, Revision 0, approved January 9, 1991, with an effective date of Apri1 8, 1991, was completed in March 1991. The material and training were found acceptable. This item is closed.

Open Item: Completion of the review, identification, documentation, and means to control and implement a preventive maintenance (PM) and surveillance tracking program for safety-related and important to safety equipment.

Coordinators and tracking mechanisms have been set up to meet the requirements of DPSOLs 1925, 1926, and 1851A, B, and C. These programs and the Works Management System (WMS) establish the mechanisms for the identification of preventive maintenance and maintenance-related surveillance activities. K-Area Standing Instruction D-70, "DPSOL Schedule and Compliance", Revision 0 , dated February 13, 1991, has been implemented by Reactor Operations to track the completion of surveillances required to meet Technical Specifications. This program ensures that the surveillance requirements, which may include an appropriate maintenance function, are identified for completion. RD-3.1/DMP-3.01, Work Control Manua1, Revision 5, dated June 15, 1991, nstablishes the mechanisms through which to implement most PM. 0ther PM and surveillance requirements are implemented using DPSOLs that are identified and called out by the tracking DPSOLs or WMS. This item is, therefore, closed.

Open Item: No integrated program exists to ensure the availability and update of all the needed reference material, drawings, and manuals for planning and maintenance personnel.

Recently implemented procedure RDP-15.02, "Controlling Documents", Revision 0, dated March 15, 1991, establishes the Reactor Restart Division-wide controls and distribution requirements for controlled documents in the Reactor Areas. The document control process identified in this instruction provides the mechanisms to make available the necessary controlled documents needed to properly plan and perform maintenance activities. DPSOL 338-206-1, Revision 2, dated May 1, 1990, is a Reactor Maintenance Department procedure implemented to ensure that documents are controlled during use by maintenance personnel. This item is closed. 
Open Item: Provide for DOE review the plan that will address the remaining procurement-related corrective actions identified in the self-assessment.

This was inadvertently identified as an open item. An acceptable plan and schedule for addressing procurement-related corrective actions identified in the self-assessment were included in the Reactor Maintenance Improvement Plan (MIP).

Open Item: Revise DPSOL 338-212-1 or other procedures to adequately address the requirements for measuring and test equipment (M\&TE) use and control, including control and recalibration of contaminated M\&TE, and the method of identifying and tracking for recalibration all M\&TE.

A recently implemented revision of DPSOL 338-212-1, "Control of Measuring and Test Equipment", Revision 3, dated May 14, 1991, contains measures to protect M\&TE from becoming contaminated. Also included are directions for the handling of contaminated M\&TE with regard to storage and cross checking. Facilities have not been provided for the recalibration of M\&TE which have become contaminated. Plans have been developed for the creation of a contaminated instrument calibration facility, but construction of this hot $1 a b$ is not a restart issue. DPSOL 338-212-1 provides interim guidance for the control of contaminated equipment through the use of cross checks, supporting documentation, and the NCR process. DPSOL 338-212-1 establishes the WMS as a means to uniquely identify and track each piece of M\&TE and to call out those pieces of M\&TE which are coming due for calibration. This item is closed.

Open Item: Develop a near-term process for tracking and alıalyzing recurring maintenance activities.

WSRC Reactor Restart Division has established a critique and reporting process for all events and unplanned occurrences. RD-2.1, RRD Administrative Manual, "Critique Procedure," Revision 0, dated July 13, 1990, provides a systematic process for the initiation of the analys is of events and unplanned occurrences, including those related to maintenance. The critique process provides the mechanism to identify initial corrective actions and evaluates the event or occurrence for input into the Occurrence Reporting System for more detailed followup and long-term analysis. RD-9.02, RRD Administrative Manual, "Occurrence Reporting System", Revision 2, dated January 1, 1991, provides the mechanism and process for the performance of detailed root cause analys is of those occurrences which are classified as Emergency or Unusual Occurrences in accordance with the applicable DOE reporting requirements. Both of these programs have provisions and guidance for the collection of information, analys is of information, cause determination, corrective action, and corrective action followup. RD-9.02 identifies the requirements for occurrence Investigators, those individuals responsible for the investigation of root cause of assigned occurrences. Those requirements include root cause analysis training. Therefore, maintenance personnel who investigate events and occurrences are required to be trained in root cause analysis. Selected Reactor Maintenance personnel have received site training on root cause determination. 
A near-term program, described in memorandum RRD-RMK 910450, dated June 21, 1991, has been developed by the Reactor Maintenance Department to perform maintenance tracking and trending activities. The program evaluates all corrective maintenance activities performed and entered into the WMS since January 1991 and then monthly thereafter. The program will categorize failures as procedure deficiency, component failure due to material deficiency, or human error due to inadequate maintenance or improper operation. Two or more failures will be reported in an equipment trending report which is to be evaluated by engineering. This item is closed.

Open Item: Development of appropriate post-maintenance testing (PMT) matrices, and implementation of the PMT procedure.

The Maintenance Improvement Plan, OPS-RMK-900580, Revision 0, dated August 27, 1990, provided a plan and schedule to develop and implement, prior to restart, a post-maintenance test program to address the corrective actions identified in the WSRC maintenance self-assessment. WSRC maintenance self-assessment corrective actions are addressed in manual R-3.2, "Reactor Restart Division Reactor Maintenance Administrative Procedures," procedure RP-3.1003, "Post Maintenance Testing," approved January 9, 1991, with an effective date of Apri1 8, 1991. Manual RD-3.1, "Reactor Work Control Procedures Manual," procedure DMP-3.01, "Work Control," Revision 5, approved June 1, 1991 and effective June 15, 1991, and RP 3.1003 provide basic guidance and structure to implement the post-maintenance test program. Administrative guidance for the development of PMT requirements for each piece of equipment is specifically addressed by RP 3.1003. The specific equipment-based PMT requirements take the form of PMT matrices. The DOE staff reviewed a sample of approved matrices. These documents provide detailed PMT requirements related directly to specific pieces of equipment and to the planned or completed maintenance artivity. This item is closed.

Open Item: No process has been identified for analyzing and trending data for all safety-related and important-to-safety lube oil systems to detect equipment degradation.

RD-3.1, DMP 3.06, "Reactor Maintenance Preventative Maintenance Program," Revision 0, was approved on August 7, 1991 and made effective on September 16, 1991. This procedure establishes the responsibilities and administrative controls for the development and implementation of the Preventive Maintenance program. Included within the program are requirements to identify and develop predictive maintenance tasks for lubrication analys is which include monitoring lubricating oil for wear products and proper lubrication properties. This item is closed.

All open items have been resolved for this issue. 
Open Item: Formal approval of the SRS Emergency Plan.

WSRC 6Q, "SRS Emergency PIan," Revision 2, was approved by DOE on September 7, 1991. This item is closed.

Open Item: The Central Control Room (CCR) staff, Operations Support Center (OSC) staff, and Security do not appear to have any specific authorities, responsibilities, or relationships to the organization at the site emergency facilities.

The CCR and OSC Staff authorities, responsibilities, and relationships to the site organization are through the Area Emergency Coordinator (AEC) as shown in WSRC 6Q7, "Reactor Area Emergency Plan," Revision 1, dated September 4, 1991, and approved by DOE on September 21, 1991. Specific emergency duties for the CCR and OSC staff are shown in the emergency response organization (ERO) table contained in WSRC 6Q7. WSRC 607 al so outlines the responsibilities of the Security staff, which are through the Protective Force Supervisor. Wackenhut Services Incorporated (WSI) and WSRC have a Memorandum of Understanding, "Interface Protocol Document - Memorandum of Understanding - Security and Support Services Agreements at Savannah River Site - Westinghouse Savannah River Company and Wackenhut Services, Incorporated," dated January 1990, which establishes the emergency preparedness relationships between the two organizations. WSI procedure ESOP 2-203, "Operations Emergencies," Revision 4, dated July 12, 1991, outlines the specific protective force responsibilities during operations emergencies. Therefore, this item is closed.

Open Item: Provide for a sufficient supply of high range dosimeters to adequately monitor personnel in the CCR and OSC.

The staff has reviewed EPIP 6Q7-303, "Emergency Equipment and Supplies," Revision 1, dated August 13, 1991, approved by DOE on September 12, 1991, and determined that an adequate number of high-range dosimeters is identified. This item is closed.

Open Item: DOE review of DPSOL 292-419, "Plant HP Emergency Equipment Audit," and Medica 1 Department Manual 3Q-7.

Procedure Manual Q1-1, Procedure 419, "Plant HP Emergency Equipment Audit," Revision 2, dated April 15, 1991, formal1y DPSOL 292-419, was reviewed by the staff and determined to be adequate for auditing the plant HP equipment. Maintenance and inventory audit requirements for medical equipment are not contained in Medical Department Manual 3Q7, however, the staff's review of EPIP 6Q7-303 identified sufficient information to address first aid and rescue equipment maintenance and inventory audits. Therefore, this item is closed.

Open Item: EPIP 6Q7-303, "Emergency Equipment and Supplies," does not address either the inventory of rescue equipment or periodic testing of the OSC telephones to ensure readiness. 
EPIP 6Q7-303 was revised and now contains sufficient information to address first aid equipment, rescue equipment, and OSC telephone testing and audits. This item is, therefore, closed.

Open Item: A site evacuation procedure, or equivalent, is needed, including the establishment of the mechanisms for transporting evacuees from rally points to a host location, identification of evacuation routes from each SRS facility, and accommodations at the host facilities.

The staff has reviewed CSWE Procedure SOP 9-36202 Manual Y10.9, "Relocation of Personnel from Rally Points," Revision 1, dated September 1, 1991, and has determined that it addresses these areas. Therefore, this item is closed.

Open Item: Develop job specific qualification requirements so that requisite knowledge, skills, and qualifications can be verified for personnel assigned to Emergency Response Organization (ERO) positions.

The DOE staff reviewed the ERO categories against WSRC 6Q7, and a 1isting of Emergency Functions vs "Normal Positions" was developed. For all the requisite positions, a selection, training, and qualification statement was found in DPSOP-38, "Reactor Training and Procedures," Revision 35, dated october 12, 1990. Where specialized training was required, it was found to exist in EPIP 6Q7-302, "Emergency Response Organization and Emergency Training," Revision 1, dated September 9, 1991, approved by DOE on September 22, 1991, and WSRC EPIP 6Q7-102, "Emergency Response Team Dispatch," Revision 1, dated March 26, 1991. Therefore, this item is closed.

Open Item: Define the number of each type of personnel comprising the ERO, and provide required information on 1-hour augment personnel as well as the onsite/offsite locations from which they are obtained.

The staff reviewed WSRC $6 Q 7$ and determined that the ERO was defined with the number and type of personnel required. WSRC $6 Q 7$ also contains information for 30 minute and 1-hour augmentation personnel, as well as the locations from which they are obtained. Therefore, this item is closed.

Open Item: Communications links between the area and site facilities are not clearly addressed.

The staff reviewed WSRC $6 Q 7$ and EPIP 6Q7-302, and concluded that they adequately define the communication links between the area and site facilities. Therefore, this item is closed.

Open Item: Communicator ERO positions have not been identified, and specific information requirements have not been addressed.

The staff reviewed WSRC $6 Q 7$ and EPIP 6Q7-302, and concluded that they adequately identify the communicator ERO positions and address specific information requirements. Therefore, this item is closed. 
Open Item: Formal approval of emergency plan implementing procedure (EPIP) 6Q7-001.

EPIP 6Q7-001, "Emergency Classification," Revision 1, dated September 6, 1991, was approved by DOE on September 24, 1991. Although the DOE staff's review determined that EPIP 6Q7-001 contains sufficient details to properly classify abnormal plant conditions, the lack of a "LOCA with degraded core" Emergency Action Level (EAL) lead to the requirement for an additional plant operating restriction, i.e., the Total Stack Activity Monitor (TSAM) will be included in Revision 5 of the plant Technical Specifications. Until the TSAM is formally included in the Technical Specifications, its operability requirements will be defined by the Plant Operating Specifications, a K-Reactor document which contains details similar to the Technical Specifications and carries equal weight in plant operations. Additionally, a future plant modification is being planned to add a redundant TSAM. With the confinement design, the inclusion of the TSAM in the Plant Operating Specifications will ensure adequate monitoring of radiological releases and acts as a satisfactory indicator for the "LOCA with degraded core" EAL. Therefore, this item is closed.

Open Item: Directly address the line-of-succession for the emergency coordinator position to the site level.

The staff reviewed WSRC $6 Q 7$ and EPIP 6Q7-001, and determined that there is a defined line-of-succession for the emergency coordinator position to the site level, i.e., the Technical Support Center (TSC) Manager. Therefore, this item is closed.

Open Item: Revise the Reactor Area Emergency PIan (RAEP) and response EPIPs as needed to incorporate emergency classification as a non-delegable responsibility.

The staff reviewed WSRC $6 Q 7$ and EPIP 6Q7-001, and has established that emergency classification is clearly stated as a non-delegable duty of the Area Emergency Coordinator. Therefore, this item is closed.

Open Item: In the RAEP and response EPIPs the discussion on the transmission of information about the nature and magnitude of hazardous material releases into and out of the reactor building, as well as a description of intra-area information flow, is unclear and incomplete.

The RAEP (WSRC 6Q7) and response EPIPS have been revised and clearly address the nature and magnitude of hazardous material releases. EPIP 607-001, Attachment 8.2, provides explicit descriptions for various radiological, toxic, flammable and explosive release conditions into and out of the reactor building. Intra-area information flow is addressed in EPIP 6Q7-002, "CCR Staff Actions for Declared Emergencies, "Revision 1, dated March 26, 1991, and EPIP 6Q7-101, "Operations Support Center Activation and Operations," Revision 2, dated September 11, 1991, approved by DOE on September 22, 1991 . These EPIPS describe information flow between the Area Emergency Coordinator 
(AEC) in the Center Control Room (CCR) and the Operations Support Center (OSC) Coordinator in the OSC. EPIP 6Q7-102 addresses communications between the OSC and the emergency teams. Therefore, this item is closed.

Open Item: There is a lack of guidance in the RAEP and response EPIPs on the type of information that is exchanged.

Specific guidance for transmitting the emergency action levels and hazardous release information is contained in EPIP 6Q7-001. Additional guidance is contained in checklists attached to EPIP 6Q7-102 for briefing emergency response teams. Therefore, this item is closed.

Open Item: The applicable Reactor Area response EPIPs should be revised to include guidelines on types of information and frequency of communications regarding the nature and magnitude of hazardous material release into and out of the reactor building, including communications from the reactor area to the TSC, periodic briefings by the AEC to the CCR staff and OSC Coordinator, and periodic briefings by the OSC Coordinator to the OSC staff.

EPIP 6Q7-001, EPIP 6Q7-002, EPIP 6Q7-101, and EPIP 6Q7-102 were reviewed and found to address types of information and the frequency of communications regarding the nature and magnitude of hazardous material release into and out of the reactor building. These procedures address communications from the reactor area to the TSC, periodic briefings by the AEC to the CCR staff and OSC Coordinator, and periodic briefings by the OSC Coordinator to the OSC staff. Therefore, this item is closed.

Open Item: Protected Area personnel accountability, in the event that crash gates are used and/or the key card reader system fails, is not addressed in the RAEP.

The staff evaluated EPIP 64/-202, "Evacuation and Accountability," Revision 3, dated September 19, 1991, approved by DOE on September 22, 1991, and

determined that provisions are now in place for personnel accountability for individuals who use the crash gates. This has been accomplished by the addition of a Rally Point Coordinator to the ERO who communicates with the Central Control Room. Also, as a result of the manual personnel accountability system described in EPIP 607-202 and K-Area Standing Instruction No. A-16, K-Reactor Protected Area Accountability Process," Revision 0, dated September 19, 1991, the failure of the key card reader system will no longer affect the personnel accountability process. Therefore, this item is closed.

Open Item: Complete an implementation plan which details the extent of work required and obtain DOE approval for implementation of Public Address (PA) System upgrades.

The staff reviewed and approved the implementation plan for long term PA System upgrades provided in WSRC-TR-91-451, "K-Area Public AddresS (PA) System Upgrades, Project Problem 01-6286; REA 90-104," Revision 0, dated July 30, 1991, which details the extent of work required to address PA system coverage of "dead spots." Therefore, this item is closed. 
Open Item: Identification of present provisions for ensuring that up-to-date Emergency Preparedness (EP) and engineering documents will be available for emergency response to reactor incidents needs to be addressed in the SRS Emergency Plan, the RAEP, and/or appropriate EPIPS, and the staff needs to review Document Control Center procedures to ensure controlled distribution of EP documents is satisfactory.

The staff reviewed document listings for the K-Area field file, which identifies controlled documents that go to the Satellite Document Control Center ( $S D C C$ ) and documents that go to the Document Control Center (DCC). The staff was satisfied that an adequate inventory of documents to support the Emergency Program are being sent to the SDCC and DDC. WSRC 6Q and 6Q 15.2, "Savannah River Site Operations Facility (SRSOF) Emergency Procedures Manual," EPIP-300, "SRSOF Operations," Revision 1, effective March 11, 1991, ensure up-to-date documents and personne?, to support the TSC and Emergency Operations Facility (EOF) coordination with Reactor personnel, are available for emergency operations. This item is closed.

Open Item: Revise EPIP 607-001, "Emergency Classification," to correct deficiencies in DP'SOL 100-4000, "Emergency Action Levels."

The staff has reviewed revised (Revision 1) EPIP 607-001, and its Technical Basis Document (TBD), WSRC-TR-90-42-126, "Technical Basis for EPIP 6Q7-001, "Emergency Classification, Revision 1," Revision 1, dated September 3, 1991, and determined that the deficiencies identified in DPSOL 100-4000, "Emergency Action Levels (EALS)" have been corrected. Therefore, this item is closed.

Open Item: Approval of the Technical Basis Document (TBD) for the Emergency Action Level (EAL) indicators identified in EPIP 6Q7-001.

The staff has reviewed and approved the Technical Basis Document, WSRC-TR-90-42-126, for the EAL indicators identified in EPIP 6Q7-001 and determined that the TBD provides adequate technical justification for the EAL indicators. Therefore, this item is closed.

Open Item: Issuance of Reactor Training and Procedure (RTAP) group procedure that directly links a change in an Emergency Action Level (EAL) to a corresponding Technical Basis Document (TBD) revision.

The WSRC Emergency Preparedness Section, rather than RTAP, is responsible for ensuring that a link exists between the EAL procedure, EPIP 6Q7-001, and the asSociated TBD, WSRC-TR-90-42-126. The staff reviewed WSRC 6Q7 and EPIP-301, "Document Preparation and Control," Revision 0, dated September 20, 1991, approved by DOE on September 22, 1991, and determined that they adequately identify the direct link between a change in an EAL and a corresponding TBD revision. Therefore, this item is closed.

Open Item: A formal mechanism to ensure that DOE approval is obtained prior to changing existing Reactor Area EALs or implementing newly developed EALs does not exist. 
The staff reviewed WSRC $6 Q 7$ and EPIP 6Q7-301, and found that they provide specific instructions requiring WSRC to obtain DOE concurrence on any changes to existing Reactor Area EALs (EPIP 6Q7-001), implementing newly developed EALs, or revision to the EAL procedure, followed by final DOE approval of both the EAL and the TBD, WSRC-TR-90-42-126. Therefore, this item is closed.

Open Item: Revise the EPIPs to specifically address performing habitability surveys in the Security Tactical Operations Center or other security personnel locations.

The staff has reviewed EPIP 6Q7-101 and concluded that it requires the Health Protection (HP) Coordinator to dispatch HP personnel to 701-1K and 701-2K if conditions warrant, i.e., plume blowing towards these buildings or gamma shine considerations. Therefore, this item is closed.

Open Item: The staff reviewed EPIP 6Q7-202, "Accountability and Evacuations," and noted that the procedure does not address protected area personnel accountability in the event that the crash gates are used or the key card reader fails.

The staff evaluated EPIP 6Q7-202, Revision 3, and determined that provisions are now in place for personnel accountability for individuals who use the crash gates. This has been accomplished by the addition of a Rally Point Coordinator to the ERO who communicates with the Central Control Room. Also, as a result of the manual personnel accountability system described in EPIP 607-202 and K-Area Standing Instruction No. A-16, the failure of the key card reader system will no longer affect the personnel accountability process. Therefore, this item is closed.

Open Item: Identify and provide procedure(s) or document(s) which address posting locations of permanent evacuation signs in the $K$-area, and provide for periodic inspection to ensure signs and routes are maintained in a readiness condition.

The staff reviewed EPIP 6Q7-303 and has determined that it adequately addresses permanent evacuation sign posting locations and provisions for periodic surveillances. Therefore, this item is closed.

Open Item: Provisions to assure the availability of the engineering documentation and the emergency preparedness documentation to the Technical Support Center (TSC) and Emergency Operations Facility (EOF) for coordination with Reactor Area personnel in the mitigation of accidents have not been addressed.

The staff reviewed document listings for the K-Area field file, which identifies controlled documents that go to the Satellite Document Control Center (SDCC) and documents that go to the Document Control Center (DCC). The staff was satisfied that an adequate inventory of documents to support the Emergency Preparedness Program are being sent to the SDCC and DCC. WSRC $6 Q$ and 60 15.2, EPIP 300, ensure up-to-date documents and personne1, to support the TSC and EOF coordination with Reactor personnel, are available for emergency operations. This item is closed. 
Open Item: Provide clarification on specific communications links for technical information transfer between the TSC and Reactor Area and the EOF and $H Q$ Emergency Operations Center (EOC).

The staff reviewed WSRC $6 Q$ and $6 Q 15.2$, EPIP 300 , and concluded that they adequately address the technical communication link between the TSC and Reactor Area and the EOF. Technical data transfer to the HQ EOC is performed via commercial telephone by the offsite Interactions Group. Additionally, the Graded Exercise Report, "DOE-SR Independent Evaluation of the Apri1 24, 1991 K-Reactor Graded Exercise," dated June 1991, indicated adequate transfer of data over the established networks. This item is closed.

Open Item: The policy for assignment and distribution of pagers or page-comm type radio receivers to remote workers must be determined, implementation procedures developed, and training conducted.

The staff reviewed WSRC $6 Q$ and noted that it contains the policy for assignment and distribution of pagecom equipment to remote workers. WSRC Q12, SRSOC 102, "Savannah River Site Operations Center (SRSOC) Rout ine Occurrences Manual, "Revision 0, dated February 20, 1991, describes notification of remote workers to the Savannah River Site Operations Center (SRSOC) personnel. Furthermore, the staff reviewed implementing procedure WSRC Manual 1B, MRP 4.03, "SRS Remote Worker Notification," dated April 30, 1991, and concludes that it adequately provides for the assignment and distribution of the pagers and instructions for their use. Attachment 2 of MRP 4.03 is signed by the worker acknowledging that the procedure has been read, thus eliminating the need for training. This item is closed.

Although not associated with an open item, the following information is provided concerning training and emergency drills and exercises.

While the restart criterion on staffing and training, contained in SER Section 15 , does not explicitly require that emergency response organization (ERO) training include practical, position-specific experience obtained through participation in emergency drills and exercises, WSRC 6Q and WSRC 6Q7 contain a commitment to provide such training. Furthermore, the restart criterion on emergency drills and exercises, also contained in SER Section 15, requires that emergency drills and exercises be conducted prior to restart, and at least annually therefore, clearly providing ERO personnel with practical, position-specific experience through participation in emergency drills and exercises. Training on hazardous material exposure estimates for accidents at the K-Area is unnecessary since it has been established that there are no significant quantities of non-radioactive hazardous materials in the K-Area, as documented in SER Supplement 1.

With regard to emergency drills and exercises, EPIP 6Q7-304, "Drills and Exercises," Revision 0, dated March 21, 1991, and Q9-5 EPAP 103, "Drill/Exercise Coordination and Conduct," lievision 0, dated September 20, 1991 , require that personnel protection be demonstrated, including minimization of personnel exposure to hazards.

There are two open items remaining to be resolved for this issue. 


\section{REMAINING OPEN ITEMS}

\subsection{DOE Management and Program Oversight}

Open Item: Revise performance elements in the SRSPO and SRRO Performance Appraisal Plans (PAPs) to include the concept that environment, safety, and health (ES\&H) considerations are to be more heavily weighted than production. 


\subsection{Issues Management and Resolution}

Open Item: Complete full development of the Action Item Management System (AIMS) program, including related implementing instructions and procedures. 


\subsection{Contractor Compliance with DOE Orders}

Open Item: To verify compliance with DOE Orders, complete the review of policies, programs, procedures and their implementation, and document the results in a final, contrulled self-assessment.

Open Item: Submit, prior to restart, a schedule that supports verification of compliance with all Category I DOE Orders.

Open Item: All CSAs and exemptions shall be approved by DOE, or corrective actions approved and completed, for all Category I Order non-complianse items prior to K-Reactor restart.

Open Item: Incorporate DOE comments into and formally issue procedure MRP 3.33 , and reference it in procedure MRP 3.02 . 
Open Item: Resolve weaknesses in the Contamination Control and Monitoring Program such as: (1) insufficient documentation of a technical basis for the use (i.e., calibration) of the laboratory scalers for the determination of radioactivity on smear samples (ES\&H concern), and (2) implement a routine program to monitor equipment and facilities for tritium contamination (as is presently performed for beta-gamma and alpha emitting radioactive contamination).

Open Item: Resolve weaknesses in the Contamination Control and Monitoring for the release of material and equipment from RCAs, such as: (1) inadequate quality assurance program for measuring and test equipment, (2) insufficient documentation of a technical basis for Portable Radiation Protection Instrumentation used for measuring radiation and contamination, and (3) inadequate program for monitoring equipment for tritium contamination.

Open Item: Compliance with American National Standards Institute (ANSI) industry standard N42.18-1980, "Specification and Performance of Onsite Instrumentation for Continuously Monitoring Radioactivity in Effluents".

Open Item: Compliance with ANSI N323-1983, "Radiation Protection Instrumentation Test and Calibration".

Open Item: Compliance with ANSI Z88.2-1980, "Practices for Respiratory Protection". 


\subsection{Safety Analysis Report}

Open Item: Upgrade the safety significant chapters of the SAR and resolve all applicable pre-restart comments. 


\subsection{Technical Basel ine Program}

Open Item: Acceptability of the use of Teflon tape in selected Airborne Activity Confinement System (AACS) instrument air lines.

Open Item: Not all critical components on Technical Baseline Program (TBP) systems were included within the system boundaries. 


\subsection{Design Change Process}

Open Item: Complete the vertical slice assessment of modifications and acceptably resolve al1 associated findings.

Open Item: Submit the plan for the long-term resolution of design change control for review and approval. 


\subsection{Seismic}

Open Item: Complete a reactor site-specific soils program to evaluate the success of past grouting efforts and to characterize the dynamic properties of the underlying soils. This soils characterization program, which includes cone penetrometer tests, down-hole and cross-hole tests, laboratory testing of undisturbed soil samples, and grout-take tests, if required, will be evaluated against the seismic analysis of structures.

Open Item: Resolution of the discrepancies between the evaluation of the elbow trunnion supports on the PWS piping and the as-built walkdowns thąt show the placement and size of bolts do not conform to the design.

Open Item: Analyze and install, according to the restart criteria, the design modifications to the SSS that will allow the neutronic poison to be injected into the suction side of the primary pumps.

Open Item: Determine the validity of extrapolating the analysis of the Cooling Water System (CWS) buried steel piping for L-Reactor to the buried steel piping for K-Reactor.

Open Item: Resolve that the stresses in several support components for the PWS heat exchangers were found by a DOE staff analys is to exceed the SER restart criteria.

Open Item: Finalize the analysis of the thermal loads and the revised nozzle loads for the Bingham pumps.

Open Item: Completion of the review of the operability of active valves.

Open Item: For equipment qualified by walkdown, justification is not provided for the safety factors.

Open Item: For equipment qualified by walkdown, valve anchorage requirements are not provided. 


\subsubsection{Control Rod Drive System Reliability}

Open Item: The new T-Amplifiers need to be demonstrated to be acceptable for their application. 


\subsubsection{Electrical Power Systems}

Open Item: Compliance with the General Restart Criteria.

Open Item: The performance capabilities of the electric power systems shall be established and evaluated for applicable design basis events, including the extent to which the electric power systems can adequately support the safety systems if the "single failure" were to occur.

Open Item: Load analyses for the GM EDGs shall be provided to establish the extent to which the electric power system can support the safety systems provided to accomplish the safety functions. These analyses shall include the identification and evaluation of: precisely which loads are important to safety, all momentary and intermittent loads, and all unique (non-redundant) loads.

Open Item: Analyses shall be provided to establish the capabilities of the dc power system to support the safety functions, including during various "blackout" scenarios. These analyses shall identify which batteries are considered important to safety, evaluate the battery sizing calculations, and evaluate the adequacy of dc system components in systems that have been provided with new larger-capacity batteries.

Open Item: Analyses shali be provided to demonstrate that the electrical protective devices for the loads and sources that are associated with automatic transfer switches have been adequately coordinated.

Open Item: A performance test shall be performed to demonstrate in an overall integrated manner that the Backup electric power systems can accommodate a complete loss of all Normal ac power to the reactor area, without any concurrent plant transient or accident. This test shall demonstrate the capability of the GM EDGs to accept the initial $\left(t_{0}\right)$ automatic loads for the non-accident case.

Open Item: The maximum "second-step" starting capability of the GM EDGs shall be demonstrated by test. This test shall serve as an indicator of the maximum load that may be manually loaded onto the EDGs subsequent to the initial loads.

Open Item: Testing shall be performed to demonstrate through repeated successful operations that "Single Unit" operation of the GM EDGs (that is, using one EDG and the EDG tie breakers to energize loads on all four emergency buses) is a viable and reliable option.

Open Item: All batteries determined to be important to safety shall be maintained and tested periodically (including once prior to restart) in accordance with the requirements and recommendations of IEEE standard 450, or its equivalent for non-lead-acid batteries. 
Open Item: The frequency of periodic test starting of the GM EDGs shall be reduced until load-testing capability is provided.

Open Item: The adequacy of the technical content of procedures related to loss-of-power situations and consistency among the procedures shall be established. 


\subsubsection{Environmental Qualification}

Open Item: Submittal of a schedule for implementation of the Long-Term Environmental Qualification Program Plan and inclusion of DOE comments. 


\subsection{Airborne Activity Confinement System}

Open Item: The completed test procedures will be reviewed upon completion of system startup testing to verify successful equipment testing.

Open Item: Adequately address the vulnerability of the system to single failures.

Open Item: The Airborne Activity Confinement System (AACS) and components shall function under the worst case DBE environmental conditions.

Open Item: Restart criteria associated with filter compartment water drain capacity, charcoal absorber adequacy, and absorber design and radiation stability have not been addressed.

Open Item: A preventative maintenance program shall be specified for both active and passive components of the AACS.

Open Item: The environmental conditions expected during and after design basis accidents have not been provided.

Open Item: WSRC needs to provide a schedule and $\mathrm{plan}$ for revised filter element testing per industry standards as outlined in American National Standards Institute (ANSI) Standards ANSI N509 and N510.

Open Item: Prohibiting the use of silicone sealants or any other temporary patching materials on filter compartments has not been adequately addressed. 


\subsection{Safe Shutdown}

Open Item: Provide the final Technical Position Paper on Safe Shutdown for DOE review and approval. 


\subsection{Fire Protection}

Open Item: WSRC approval and issuance of procedure RDP-1.11, "Reactor Areas Fire Protection Program Plan."

Open Item: WSRC provision of guidelines and criteria utilized to perform the walkdown to satisfy ROMP item DB-4.2, "Pre-Startup Certified Fire Control Engineer Walkdown."

Open Item: WSRC approval and issuance of a procedure which conforms with the requirements of National Fire Protection Association (NFPA) 51B-1984,

"Standard for Fire Prevention in Use of Cutting and Welding Processes."

Open Item: Complete procedures for surveillance of fire protection equipment.

Open Item: WSRC provision of program guidelines that will ensure removal of combustible scaffolding from the reactor.

Open Item: WSRC provision of a review document relative to firefighting procedures to assure adequacy of training, equipment, and procedures.

Open Item: Provide guidelines and criteria to be utilized in performance of a WSRC review to document the assurance that sufficient fire detection to support SRS program objectives is in the reactor building.

Open Item: WSRC does not procedurally control lube oil collection requirements.

Open Item: Completion of the safe shutdown analysis (SSA), including:

(1) the programs and procedures that maintain the SSA as a controlled document to assure that future design changes to the plant that may affect the SSA are captured and appropriately dispositioned so that the SSA assumptions and conclusions remain valid,

(2) justification for continued reactor operations with the existing vulnerabilities in the fire protection systems, and

(3) the procedural, administrative and system changes identified in the SSA.

Open Item: WSRC provision of a fully developed set of Abnormal Condition Control procedures.

Open Item: WSRC provision of a plan for life safety upgrades to be implemented prior to reactor restart.

Open Item: Formal issuance of SRS Fire Department Operations, including:

(1) the responsibilities, qualifications, training and staffing requirements for the on-site auxiliary fire brigade, 
(2) equipment requirements for the on-site auxiliary fire brigade,

(3) how and when the on-site auxiliary fire brigade is invoked,

(4) how and when the SRS fire department is invoked, and

(5) the integration and interactions of the on-site auxiliary fire brigade, the SRS Fire Department, and the Reactor Operations Department.

Open Item: WSRC provision of procedural upgrades due the changes in plant configuration concerning fire protection systems and equipment.

Open Item: Completion of necessary training programs due to changes in fire protection systems and procedures.

Open Item: WSRC provision of programmatic requirements and methodology for the readiness assessment, the reviewer criteria, and a resolution process for any findings generated during the assessment. 
10.3 Normal and Abnormal Operating Procedures

Open Item: Complete and approve Power Department procedures PDAP 5-3.1, PDAP 5-3.2, and the Procedure Writer's Guide. 


\subsection{Emergency Operating Guidel ines and Procedures}

Open Item: The EOP validation program needs to be revised to verify the operator's ability to perform certain actions within 10 minutes following initiation of a given event.

Open Item: Verification of the adequacy of the field walkdowns done for ACC procedures not validated on the simulator. 


\subsection{Notifications/Reporting}

Open Item: DOE Program Senior Official (PSO) approval required for procedures which implement the requirements of DOE Order 5000.3A. 


\subsection{Transient and Accident Analys is}

Open Item: Completion of an acceptable upgraded Safety Analysis Report (SAR) Chapter 15.

Open Item: The assumptions, input data, and analyses based on the Upgraded Thermal-Hydraulic Limits Action Plan and the Upgraded SAR Chapter 15 shall be consistent.

Open Item: Adequacy of radioactive release considerations.

Open item: Adequacy of anticipated transients without scram (ATWS) considerations.

Open Item: Proper treatment of the design basis events (DBEs) according to expected frequency of occurrence.

Open Item: The disposition of single failures that have been identified by WSRC.

Open Item: Analyses shall be checked and independently verified in accordance with appropriate Quality Assurance (QA) requirements.

Open Item: Determination of the complete set of operational limits.

Open Item: Provide sufficiently detailed information in the SAR to form the basis for technical specifications.

Open Item: Conformance with the requirements of 10 CFR 100.

Open Item: Provide a written commitment to upgrade SAR Chapter 15 1oss-ofcoolant-accident (LOCA) analyses to commercial standards, and a schedule that shows the action plans to upgrade both LOCA and non-LOCA analyses will be prepared by January 1, 1992 .

Open Item: Include in the analyses the worst credible single failures.

Open Item: Determination of setpoints.

Open Item: Assumption of conservative scram characteristics.

Open Item: The analyses for SAR Chapter 15 shall be based on the most limiting combination of neutronic and thermal hydraulic parameters.

Open Item: If operator action is required during the initial ten minutes of an event, ensure that such actions are credible.

Open Item: Demonstrate that the core can be maintained at an acceptable temperature for an extended period of time after emergency cooling system (ECS) initiation. 
Open Item: Adequate consideration in the analyses of the effects of postulated accidents on other systems.

Open Item: Demonstrate that fuel clad integrity will be maintained throughout a11 DBES.

Open Item: Assess the potential for radioactive releases due to failure of liquid-containing tanks, including consideration of radioactive releases due to accident mitigation, such as overflow to the 50 million gallon retention basin.

Open Item: Include allowances for uncertainties and modeling omissions in the fuel design limits.

Open Item: Perform a Process Water System pressure assessment, and include allowances for uncertainties and modeling omissions.

Open Item: Potential hazardous mixtures of tritium should be addressed. 


\subsection{Technical Specifications}

Open Item: Resolve issues and related safety analyses for Phase 1 and Phase 2 Technical Specifications, and submit revised Technical Specifications to DOE for review and approval. 


\subsection{Power Limits}

Open Item: Resolve Emergency Cooling System (ECS) power limits methodology using, as needed, additional information from ongoing modeling, benchmarking, and experimental efforts.

Open Item: For the ECS phase large break loss-of-coolant accident (LBLOCA), determine the acceptable power level limit that results in a reasonable probability that no fuel assembly is damaged.

Open Item: Establish an appropriate safety margin for the gamma heating phase.

Open Item: Document that there are no heat flux dependent local surface phenomena that can initiate onset of thermal excursion (OTE) for the ECS phase.

Open Item: For the gamma heating phase, document the reference analysis for power limitations and resolve a number of technical concerns, including convection with limited net air flow, and the acceptability of melting select in-core components, if contemplated as an acceptable risk.

Open Item: Demonstrate the adequacy and reliability of the sump level instrumentation.

Open Item: Address the possibility of a mini-blackout and loss of ECS due to flooding of the motor control centers (MCCS) and other equipment in the reactor building basement following a loss of pumping accident (LOPA).

Open Item: Document the technical basis demonstrating that the single failures selected by WSRC for each phase of the LBLOCA are credible and limiting.

Open Item: Confirm that credible single failure criteria have been identified and given due consideration in determining LOPA, pump shaft break (PSB), and gang rod withdrawal (GRW) power limits.

Open Item: Confirm that a break in the Process Water (PW) loop containing an ECS inlet represents the worst case break location for the ECS phase, and that specific combinations of broken loop and operating ECS lines do not combine to produce adverse flow distributions in the plenum.

Open Item: Conduct additional analysis to address the non-fuel, non-target components for gamma heating effects.

Open Item: Document the rationale justifying a smaller decay heat uncertainty for both the flow instability (FI) and ECS phases rather than using the recommended additional 20\% margin of Appendix $\mathrm{K}$.

Open Item: Demonstrate that PW pump speed, with direct current (DC) motors only, is consistent with analyses. 
Open Item: Confirm the appropriate timing of the alternating current (AC) pump trips in the event of an accident.

Open Item: Determine whether the uncertainties for the LOPA are 1arger than those associated with the gamma heating phase of the double-ended guillotine break (DEGB) LBLOCA, and provide documentation addressing those uncertainties.

Open Item: Document the heat transfer coefficients used in the ECS phase that use phase-based velocities to correlate the existing database.

Open Item: Resolve the questions regarding single and double wall heating for the ECS phase methodology.

Open Item: Fully consider the effects of irregular oxide film formation and flaking in the ECS limit-setting process.

Open Item: Document a conservative minimum assembly coolant flow rate for the ECS phase.

Open Item: Resolve the outstanding recommendations and comments on the ECS methodology and experiments from the DOE independent peer review panel.

Open Item: Demonstrate that if small quantities of aluminum-based components melt during gamma heating, that they will do so in a benign manner and not create a mini-explosion that could initiate a severe accident.

Open Item: Acceptability of the gamma heating methodology.

Open Item: For the ECS phase, verify by qualitative means that power levels dictated by minimum (worst) assembly flow values at high confidence values also will produce a low probability of fuel failure on a core-wide basis.

Open Item: The ECS uncertainty analysis needs to show that it is bounding with respect to "linear" assumptions, and that the inclusion of critical assumptions is complete.

Open Item: Provide a conservative accounting for uncertainties associated with the gamma heating power estimates.

Open Item: Provide adequate documentation to support the establishment of power limits, including:

(1) formally document the basis for the onset of significant voids (OSV) safety margin, set at 1 sigma or $84 \%$ on a core-wide basis for a single assembiy going into FI,

(2) revise the draft ECS documents to reflect the evolution of the ECS power limit methodology, especially those describing the treatment of uncertainties, and 
(3) for the LOPA, provide complete documentation that results in a defensible method, model, benchmark, safety analysis and core limit, with the safety analysis and resultant core limit fully reflecting system interaction and human factor vulnerabilities.

Open Item: Validate the accuracy of the calculated power limit values resulting from the application of the reference codes by comparison to separate confirmatory calculations, and resolve any concerns identified as a result of this effort.

Open Item: Perform a long-term evaluation of the consequences of a LBLOCA.

Open Item: Address the long-term management of potentially radioactive waste water effluents for both LBLOCA and LOPA accidents. 


\section{Emergency Preparedness}

Open Item: Correlate instrument name and number identified in EPIP 6Q7-001, "Emergency Classification", to the individual (actual) radiation monitors on site in order to properly inventory devices during future inspections.

Open Item: Implement compensatory means of providing sufficient and reliable communication for the "dead spots" until the Public Address (PA) System deficiencies are corrected. 

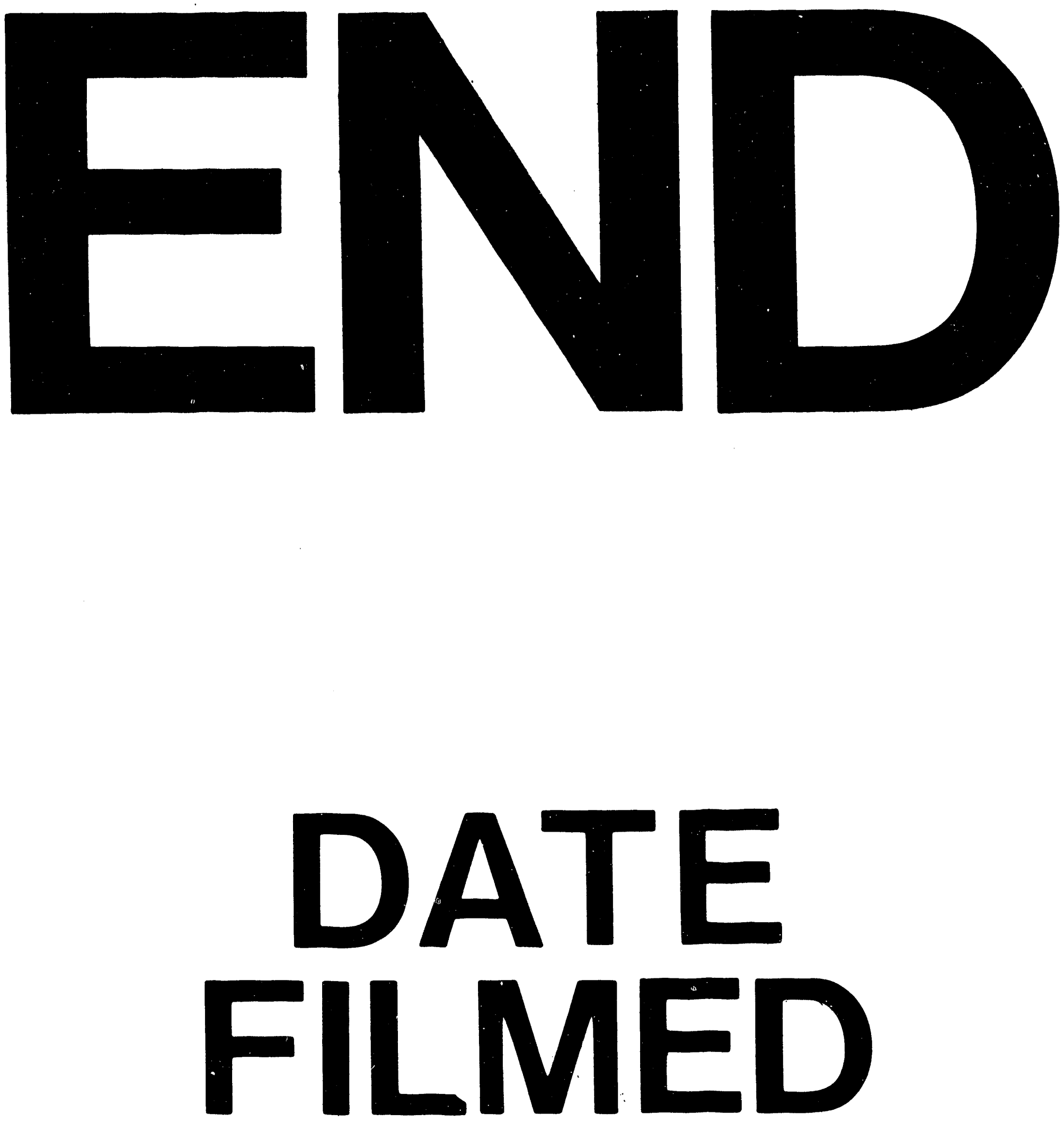

f

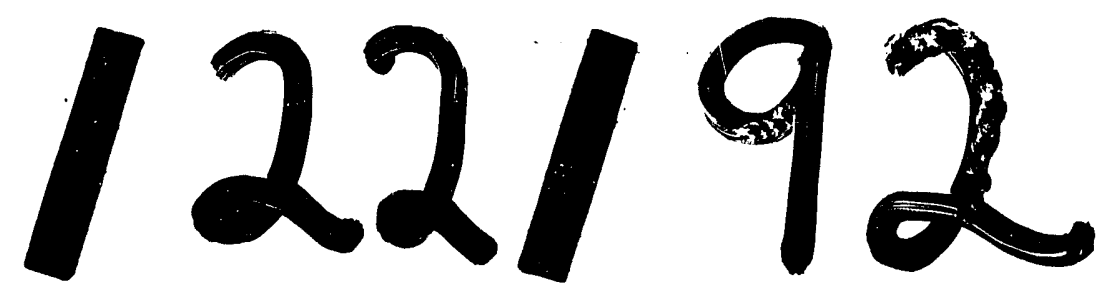

